\title{
Epidemiology of Pancreatic Cancer: Global Trends, Etiology and Risk Factors
}

\author{
Prashanth Rawla ${ }^{\mathrm{a}, \mathrm{d}}$, Tagore Sunkara ${ }^{\mathrm{b}}$, Vinaya Gaduputic
}

\begin{abstract}
Pancreatic cancer is the seventh leading cause of cancer-related deaths worldwide. However, its toll is higher in more developed countries. Reasons for vast differences in mortality rates of pancreatic cancer are not completely clear yet, but it may be due to lack of appropriate diagnosis, treatment and cataloging of cancer cases. Because patients seldom exhibit symptoms until an advanced stage of the disease, pancreatic cancer remains one of the most lethal malignant neoplasms that caused 432,242 new deaths in 2018 (GLOBOCAN 2018 estimates). Globally, 458,918 new cases of pancreatic cancer have been reported in 2018, and 355,317 new cases are estimated to occur until 2040. Despite advancements in the detection and management of pancreatic cancer, the 5-year survival rate still stands at $9 \%$ only. To date, the causes of pancreatic carcinoma are still insufficiently known, although certain risk factors have been identified, such as tobacco smoking, diabetes mellitus, obesity, dietary factors, alcohol abuse, age, ethnicity, family history and genetic factors, Helicobacter pylori infection, non$\mathrm{O}$ blood group and chronic pancreatitis. In general population, screening of large groups is not considered useful to detect the disease at its early stage, although newer techniques and the screening of tightly targeted groups (especially of those with family history), are being evaluated. Primary prevention is considered of utmost importance. Up-todate statistics on pancreatic cancer occurrence and outcome along with a better understanding of the etiology and identifying the causative risk factors are essential for the primary prevention of this disease.
\end{abstract}

Keywords: Pancreatic cancer; Epidemiology; Incidence; Mortality; Trends; Survival; Etiology; Risk factors; Prevention; Pancreatitis

\section{Introduction}

Pancreatic cancer is an intractable malignancy and is the sev-

Manuscript submitted October 23, 2018, accepted November 14, 2018

aDepartment of Internal Medicine, SOVAH Health, Martinsville, VA 24112, USA

${ }^{b}$ Department of Gastroenterology and Hepatology, Mercy Medical Center, Des Moines, IA 50314, USA

'Division of Gastroenterology, SBH Health System, Bronx, NY, USA

${ }^{\mathrm{d} C o r r e s p o n d i n g ~ A u t h o r: ~ P r a s h a n t h ~ R a w l a, ~ D e p a r t m e n t ~ o f ~ I n t e r n a l ~ M e d i c i n e, ~}$ SOVAH Health, 320 Hospital Dr, Martinsville, VA 24112, USA.

Email: rawlap@gmail.com

doi: https://doi.org/10.14740/wjon1166 enth leading cause of global cancer deaths in industrialized countries [1] and the third most common in the USA [2]. Based on GLOBOCAN 2018 estimates, pancreatic cancer has ranked the 11th most common cancer in the world counting 458,918 new cases and causing 432,242 deaths $(4.5 \%$ of all deaths caused by cancer) in 2018 [1]. Worldwide incidence and mortality of pancreatic cancer correlate with increasing age and is slightly more common in men than in women [1]. Despite advancement in the knowledge of potential risk factors that cause pancreatic cancer and newly available tools for early diagnosis, its incidence is estimated to increase and will include 355,317 new cases within 2040.

Although the cause of pancreatic cancer is complex and multifactorial, cigarette smoking [3] and family history are dominant [4]. Pancreatic cancer is mainly divided into two types of pancreatic cancer: pancreatic adenocarcinoma, which is the most common ( $85 \%$ of cases) arising in exocrine glands of the pancreas, and pancreatic neuroendocrine tumor (PanNET), which is less common (less than 5\%) and occurs in the endocrine tissue of the pancreas [5]. Pancreatic adenocarcinoma has a very poor prognosis, typically after diagnosis, only $24 \%$ of people survive 1 year, and $9 \%$ live for 5 years [6].

Based on the clinical stage of the tumor, pancreatic cancer is classified into four types: I (no spread or resectable), the cancer is limited to the pancreas and has grown $2 \mathrm{~cm}$ (IA) or greater than $2 \mathrm{~cm}$ but less than $4 \mathrm{~cm}$ (IB); II (local spread or borderline resectable), the cancer is $>4 \mathrm{~cm}$ and is limited to the pancreas, or there is spread locally to the nearby lymph nodes; III (wider spread or unresectable), cancer may have expanded to the nearby blood vessels or nerves, but has not metastasized to distant sites; IV (metastatic), cancer has spread to distant organs. Because pancreatic adenocarcinoma and the other less common exocrine cancers are typically diagnosed at a late stage (III or IV), it has a very poor prognosis compared to PanNET. At its early stages, pancreatic cancer usually lacks symptoms [7]. Upon progression of the tumor, it manifests as a gradual onset of non-specific symptoms including jaundice, weight loss, light-colored stools, abdominal pain and fatigue [8].

The available diagnostic tests are non-specific and may miss patients with early-stage disease [7]. Surgery, chemotherapy and radiotherapy are traditionally used to extend survival and/or relieve the patients' symptoms. However, for advancedstage cancer cases, there is still no definite cure [9]. There is a need for further research along with new local and systemic therapies, along with the need to assess the outcomes of these approaches. Therefore there is a necessity for ongoing evalu- 
Estimated age-standardized incidence rates (World) in 2018, pancreas, both sexes, all ages

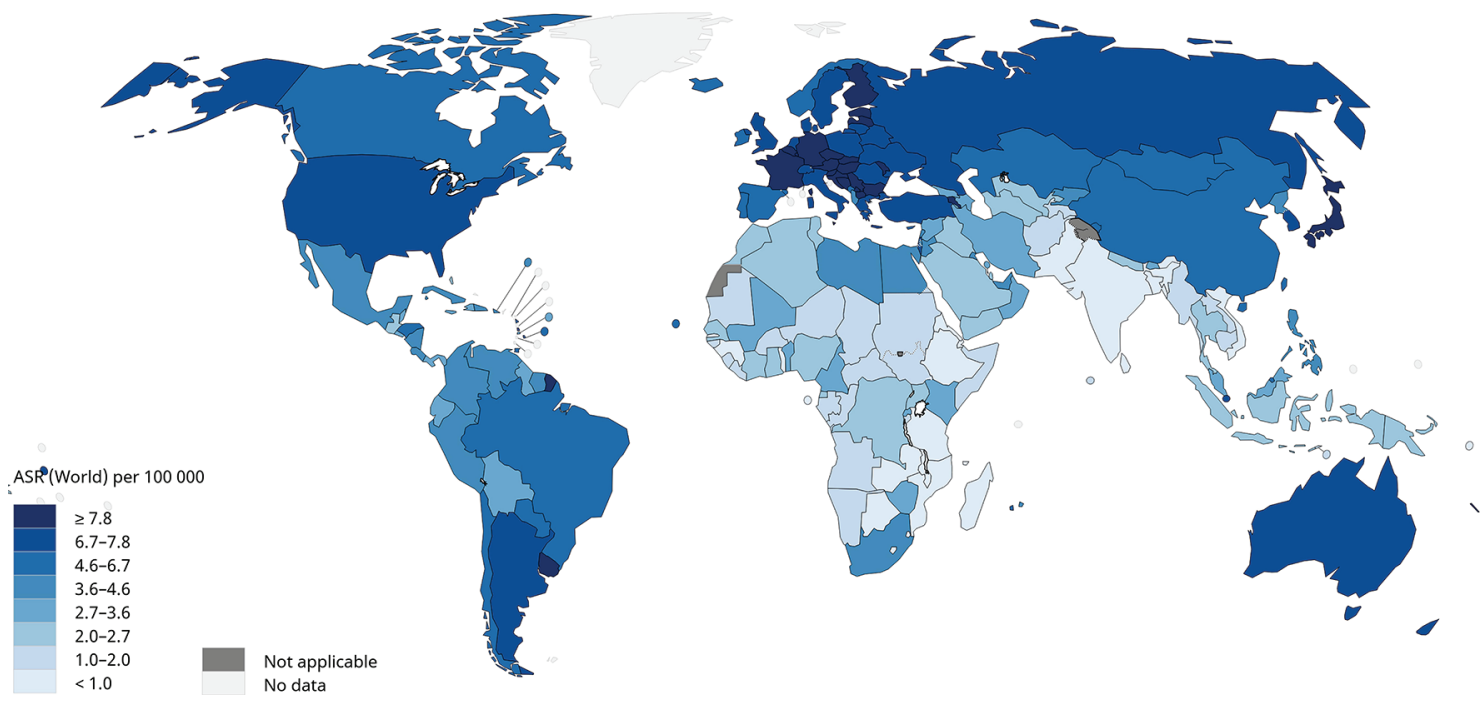

Figure 1. Map shows estimated age-standardized incidence rates (ASR) for pancreatic cancer worldwide in 2018, including both sexes and all ages (reproduced from http://globocan.iarc.fr/ [2]).

ation of the epidemiology and mortality trends of this malignancy.

\section{Epidemiology}

Analysis of pancreatic cancer epidemiology may be the key to interpreting the etiology of pancreatic cancer and thus, the cornerstone of developing an effective prevention strategy.

\section{Incidence}

The incidence of pancreatic cancer varies across regions and populations (Fig. 1). In 2018, 458,918 new cases of pancreatic cancer were registered worldwide, representing $2.5 \%$ of all cancers [1]. The age-standardized rate (ASR) incidence was highest in Europe (7.7 per 100,000 people) and North America (7.6 per 100,000 people), followed by Oceania (6.4 per 100,000 people). The lowest rate was observed in Africa with an estimated incidence of 2.2 per 100,000 people [1]. Differences in incidence rates were 30 -fold between the populations at the highest rate (Hungary: 10.8), and the populations with the lowest rate (Guinea: 0.35) (Fig. 2a).

A slight difference in pancreatic cancer incidence among genders as well as a significant different geographic distribution was observed [1]. It is more common in men (5.5 per $100,000,243,033$ cases $)$ than in women (4.0 per 100,000, 215,885 cases). In men, the risk of developing pancreatic cancer is high in Central and Eastern Europe, particularly Latvia and Republic of Moldova (15.3), Estonia (14.2) and Hungary (12.9), followed by Uruguay (12.0) and Japan (11.7), while the lowest rates are recorded in Guinea (0.23) and Malawi (0.30). The regions with the highest incidence of pancreatic cancer in women are Western Europe (7.2), North America (6.5), and
Northern Europe and Australia/New Zealand (equally: 6.4) [1]. The regions with the lowest risk (less than 1.0 per 100,000) of contracting pancreatic cancer in women are Eastern Africa and South-Eastern Asia. There is no recorded case of pancreatic cancer for both sexes in the African regions of Comoros and Sao Tome and Principe [1].

The incidence rate for both sexes increases with age [1, $10,11]$. Pancreatic cancer is seldom diagnosed before 55 years of age, and it can be defined as a disease of elderly populations because the highest incidence is reported in people over 70 years $[11,12]$.

It is not entirely clear the reason for these differences among the countries. However, it may be possible that the environment and/or the exposure to certain risk factors account for the observed geographic variation in the incidence of pancreatic cancer. For example, some findings indicate that tobacco smoking [13] may have some effects on those differences, while others indicate dietary style and obesity [1416]. Another thing to be considered is that diagnostic tools and the change in use of various diagnostic modalities vary between developed and undeveloped geographic areas [17]; furthermore, some differences in the estimated incidence may be attributed to the quality of registries, for which coverage, completeness and accuracy vary by country [18]. The reasons for the greater incidence of pancreatic cancer in men are still insufficiently known. Women are less exposed to risk factors from the environment responsible for their occurrence or are either less prone to these kinds of malignant tumors [19-21].

\section{Mortality}

International mortality rates for pancreatic cancer vary considerably in the world (Fig. 2b). In 2018, the highest mortality rates were recorded in Western Europe (7.6 per 100,000 peo- 
Estimated number of new cases in 2018, pancreatic cancer, males and females, all ages

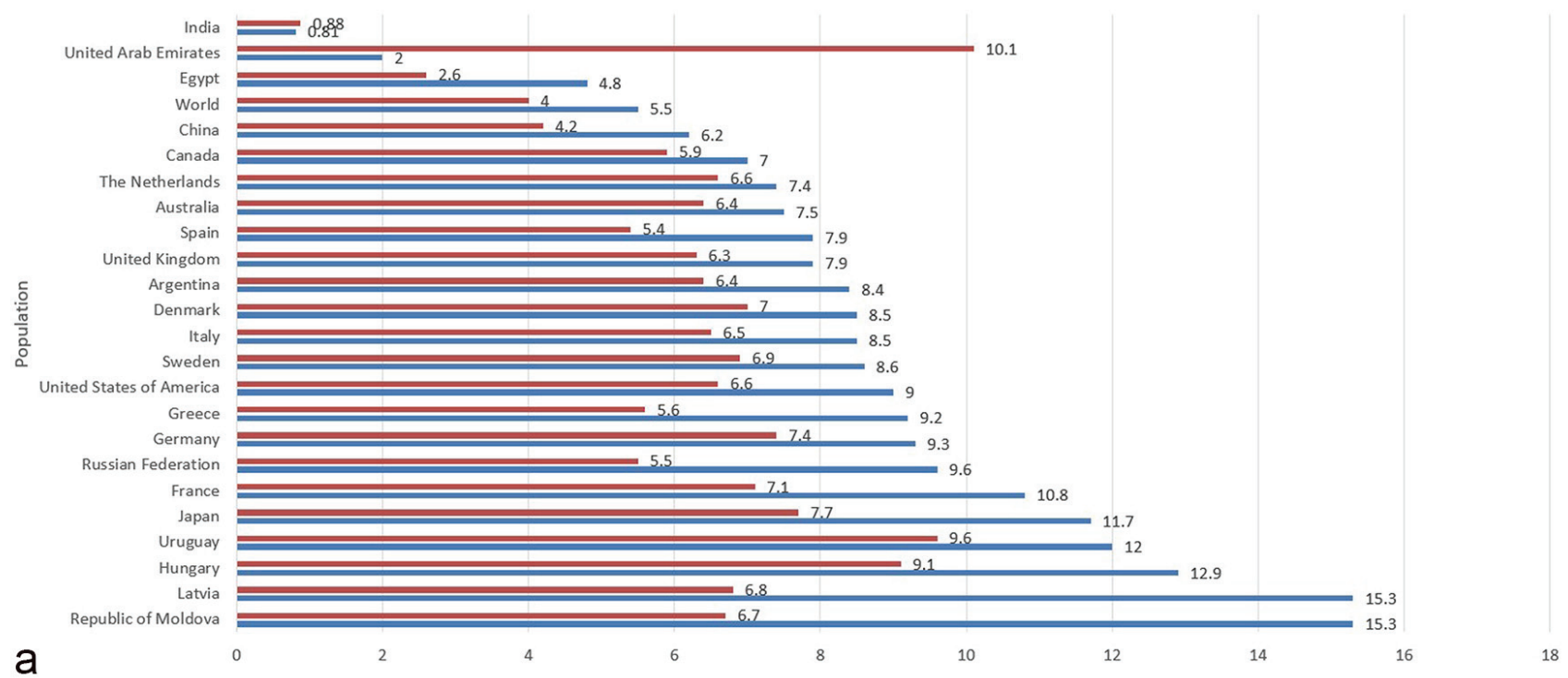

Estimated number of deaths in 2018, pancreatic cancer, males and females, all ages

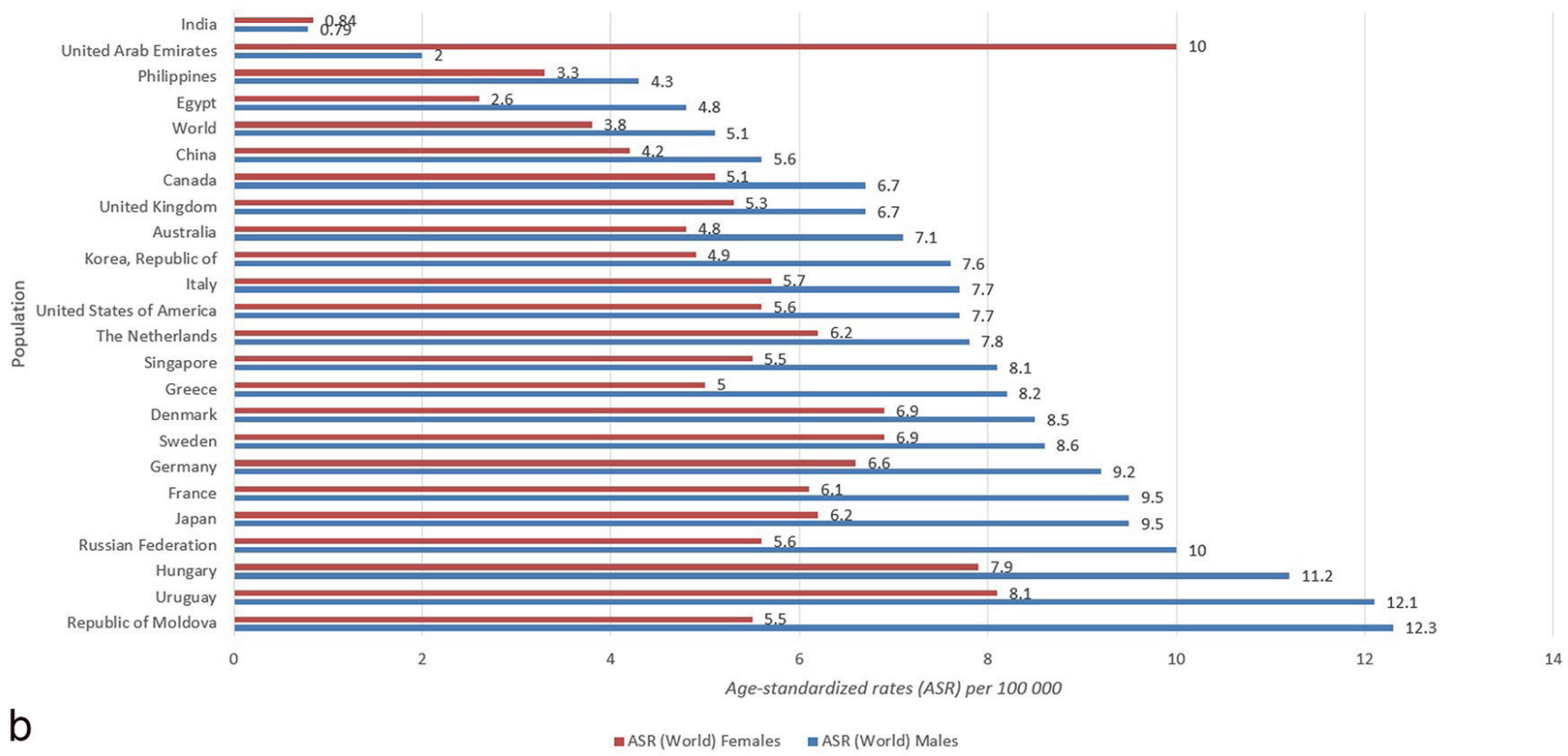

Figure 2. (a) Bar chart shows country-specific incidence age-standardized rates by sex for pancreatic cancer in 2018. Source: GLOBOCAN 2018 [2]. (b) Bar chart shows country-specific mortality age-standardized rates by sex for pancreatic cancer in 2018. Source: GLOBOCAN 2018 [2].

ple), Central and Eastern Europe (7.3), followed by Northern Europe and North America (equally: 6.5) (Fig. 3) [1]. The lowest rate was reported in the countries of Eastern Africa (1.4), South-Eastern Asia and Western Africa (equally: 2.1). The differences in mortality rates were 30 -fold between the populations with the highest and lowest rate (Uruguay versus Guinea: 9.9 versus 0.32 ). Slightly less than half of the deaths for pancreatic cancer occurred in Asia in 2018 (46.4\%, 200,681 of deaths), while slightly more than one-third were recorded in Europe $(29.6 \%, 128,045$ of deaths). More than half of deaths for pancreatic cancer were registered in the most developed countries $(52.3 \%, 226,272$ of deaths). The mortality rate of pancreatic cancer in both males and females increases with age, and almost $90 \%$ of all deaths occur after the age of 55 years [1].

In 2018, the highest mortality rates in men were recorded in Republic of Moldova (12.3) and Uruguay (12.1), while in women the mortality rates were the highest in United Arab Emirates (10.0) and Uruguay (8.1). On the contrary, the least deaths in men were registered in Tanzania (0.3) and Malawi 
Estimated age-standardized mortality rates (World) in 2018, pancreas, both sexes, all ages

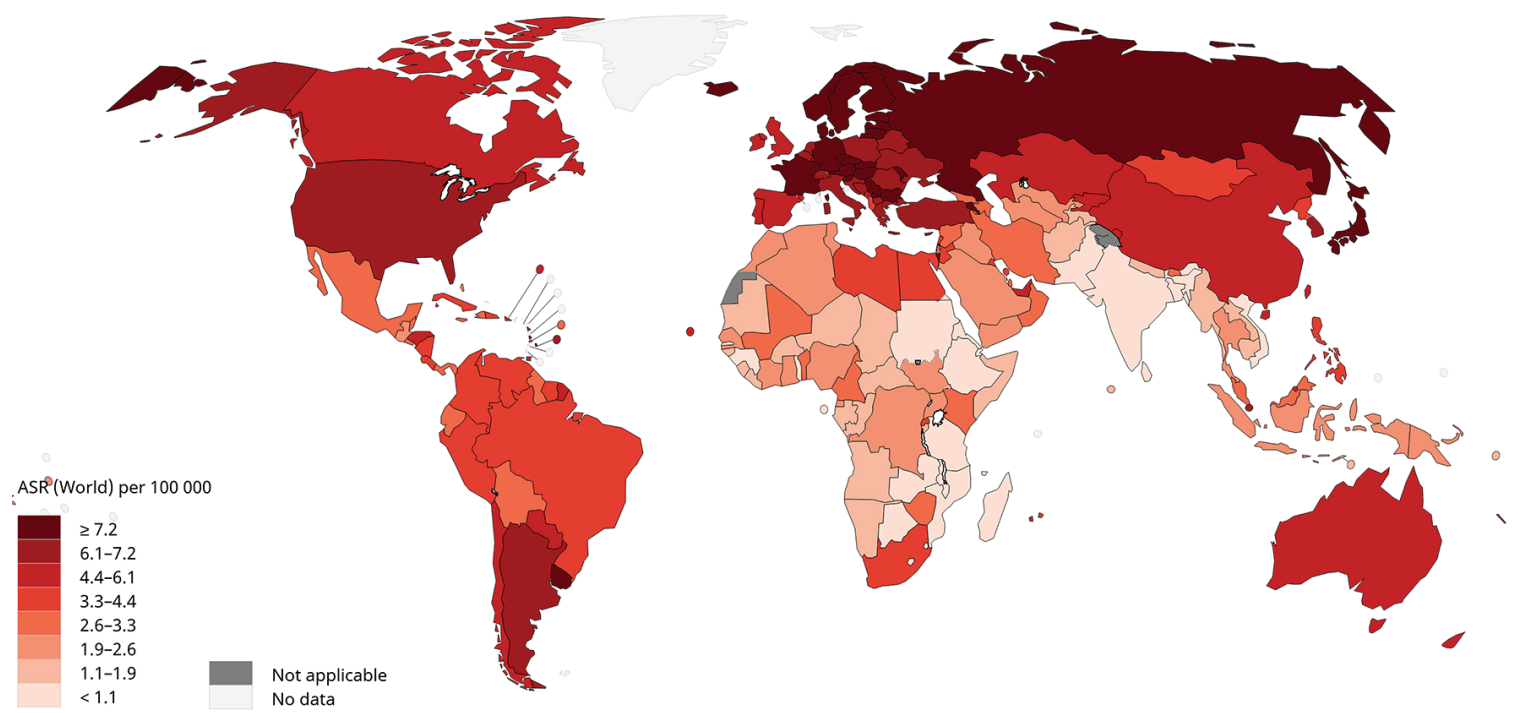

Figure 3. Map shows estimated age-standardized mortality rates (ASR) for pancreatic cancer worldwide in 2018, including both sexes and all ages (reproduced from http://globocan.iarc.fr/ [2]).

(0.32), while in women the lease death was seen in Guinea (0.2) and Pakistan (0.3). The close parallel between the incidence and mortality rates from pancreatic cancer reflects the fatal nature of this disease (Fig. 4) [22, 23]. Notably, because it is difficult to diagnose pancreatic cancer due to the lack of early symptoms, pancreatic cancer is the most common detected at the autopsy studies $[17,24] ; 80-90 \%$ of patients have unresectable tumors due to the advanced stage at diagnosis. Additionally, the current chemotherapeutic regimen available is limited and often ineffective $[12,22,25]$, especially for the adenocarcinoma that is mostly diagnosed at stage III or IV. Early detection may be the key to reduce mortality and may be supported by patients screening and prevention.

\section{Trends}

In the last decade, a trend towards an increase of pancreatic cancer incidence and mortality rates was observed regardless of the gender $[1,26]$. Analysis of statistic data reported by SEER

\section{Estimated age-standardized incidence and mortality rates (World) in 2018, pancreas, both sexes, all ages}

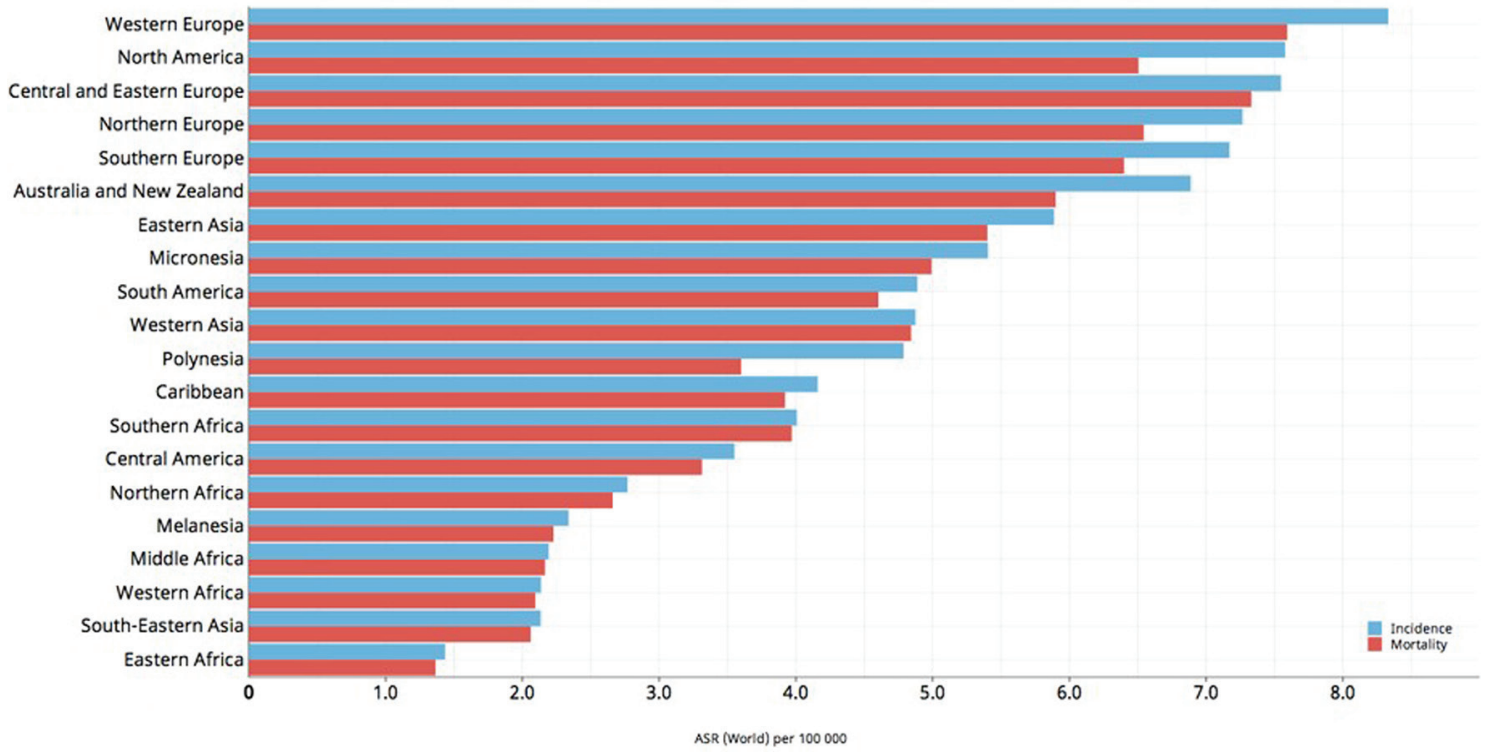

Figure 4. Bar chart shows estimated age-standardized incidence and mortality rates (ASR) for pancreatic cancer in world areas in 2018, including both sexes and all ages (reproduced from http://globocan.iarc.fr/ [2]). 


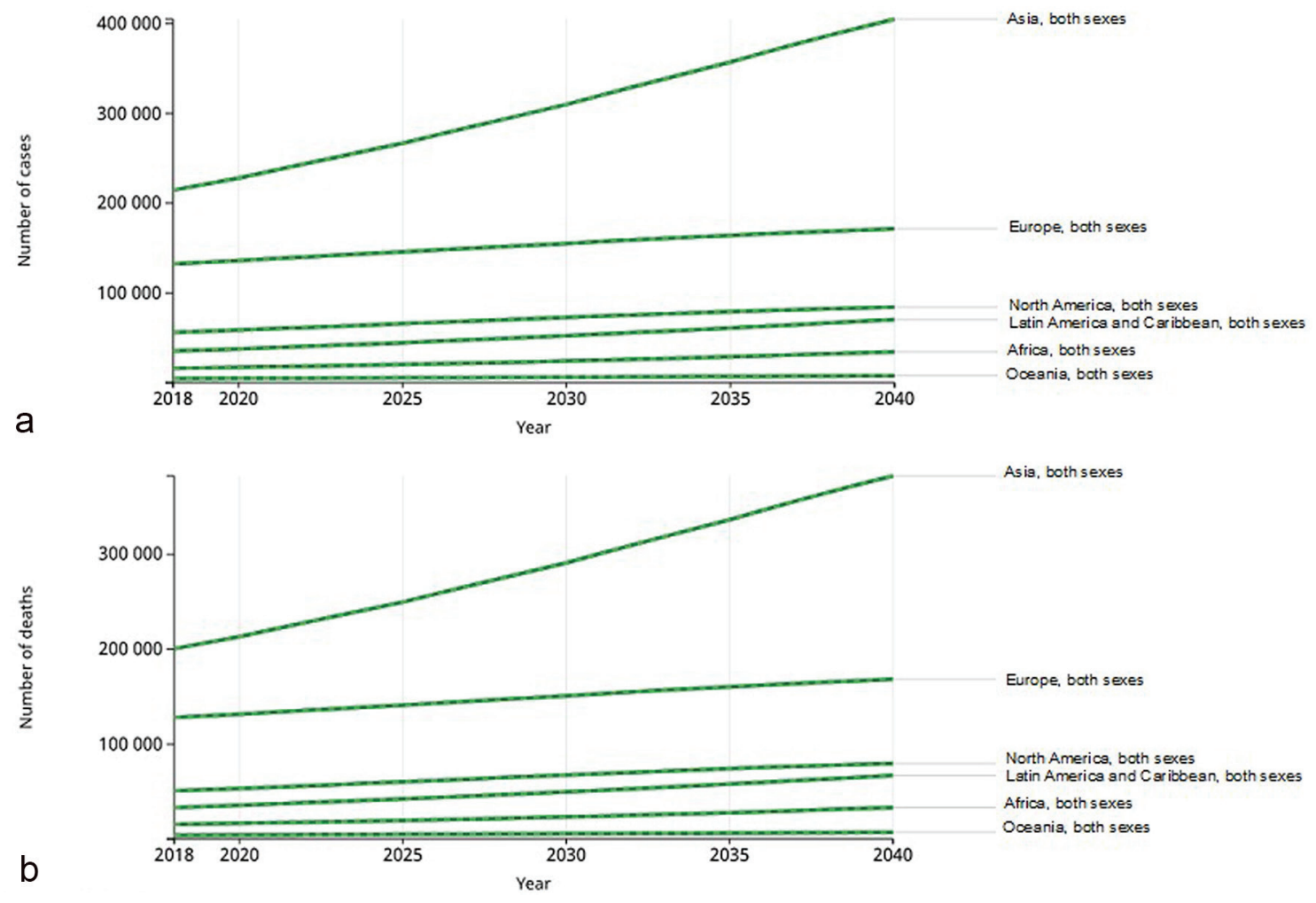

Figure 5. Trends in pancreatic cancer incidence and mortality predicted for the years 2018 to 2040 (reproduced from http://globocan.iarc.fr/ [28]). (a) Estimated incidence from 2018 to 2040, in both sexes and all ages (0 - 70+ years). Asia: 214,499 in 2018 and $+190,532$ in 2040, (+88.8\% of increase); Europe: 132,559 in 2018 and +38,855 in 2040 (+29.3\%); North America: 56,002 in 2018 and +28,325 in 2040 (+50.6\%); Africa: 16,059 in 2018 and +18,327 in $2040(+114.1 \%)$; Latin America and the Caribbean: 35,270 in 2018 and +35,007 in 2040 (+99.3\%); Oceania: 4,529 in 2018 and +3,268 in 2040 (+72.2\%). (b) Estimated mortality from 2018 to 2040 , in both sexes and all ages (0 to 70+ years). Asia: 200,681 in 2018 and +182,127 in 2040 (+90.8\%); Europe: 128,045 in 2018 and +40,444 in 2040 (+31.6\%); North America: 50,745 in 2018 and +29,011 in 2040 (57.2\%); Africa: 15,458 in 2018 and $+17,744$ in 2040 (+114.8\%); Latin America and the Caribbean: 33,311 in 2018 and +33,637 in 2040 (+101.0\%); Oceania: 4,002 in 2018 and $+2,985$ in $2040(74.6 \%)$

13 demonstrated that between years 2000 and 2014, there is an age-specific trend towards an increase in pancreatic cancer incidence in two particularly group of ages, 20 - 29 years old and $>80$ years in the USA [27]. When ethnicity-specific trends were analyzed, the incidence and mortality rates were higher in whites than in blacks patients [27], which is a reverted trend if we consider that between 1975 and the late 1990s the number of deceased for pancreatic cancer was increased among the black population and then significantly decreased [26].

Temporal trends about the pancreatic cancer incidence and mortality over the period 2018 - 2040 were abstracted from GLOBOCAN 2018. It was observed that there is a trend towards an increase of pancreatic cancer incidence ( $+77.7 \%$ with 356,358 new cases) and mortality $(+79.9 \%, 345,181$ deaths) from 2018 to 2040 (Fig. 5a) [1, 28]. These trends vary significantly internationally. The highest incidence of pancreatic cancer will be registered in Africa $(+114.1 \%)$, followed by Latin America and the Caribbean (+99.3\%). On the contrary, the lowest incidence will be registered in Europe $(+29.3 \%)$. Some regional differences will be observed between men and women. In men, the highest incidence rates will be registered in North America ( $+52.3 \%$ men versus $+48.7 \%$ women $)$ and
Europe $(+30.7 \%$ men versus $+27.8 \%$ women $)$. On the other hand, in Asia, Latin America and the Caribbean and Oceania, the highest incidence of pancreatic cancer will be registered among women (women versus men: $97.4 \%$ versus $81.9 \%$, $74.3 \%$ versus $70.0 \%$ and $101.7 \%$ versus $96.6 \%$, respectively), while in Africa, the estimated incidence will be the same in both sexes [28].

From 2018 to 2040 , the same trend is also observed for the estimated mortality rate for pancreatic cancer among continents in both sexes (Fig. 5b) and for the regional differences between men and women. Indeed, the highest mortality rate is estimated to be in Africa $(+114.8 \%)$, followed by Latin America and the Caribbean $(+101 \%)$, while the lowest incidence will be registered in Europe $(+31.6 \%)$. Additionally, in North America, Europe and Africa, the highest mortality rates will be registered in men (men versus women: $+58.7 \%$ versus $55.2 \%,+33.0 \%$ versus $+30.1 \%$ and $115.0 \%$ versus $114.5 \%$, respectively), while in Asia, Latin America and the Caribbean and Oceania, the highest mortality rates of pancreatic cancer will be registered in women (women versus men: $98.3 \%$ versus $84.4 \%, 103.4 \%$ versus $98.4 \%$ and $77.9 \%$ versus $74.6 \%$, respectively). 


\section{Pancreatic Cancer: 1971-2011}

Age-Standardised One-Year Net Survival, England and Wales

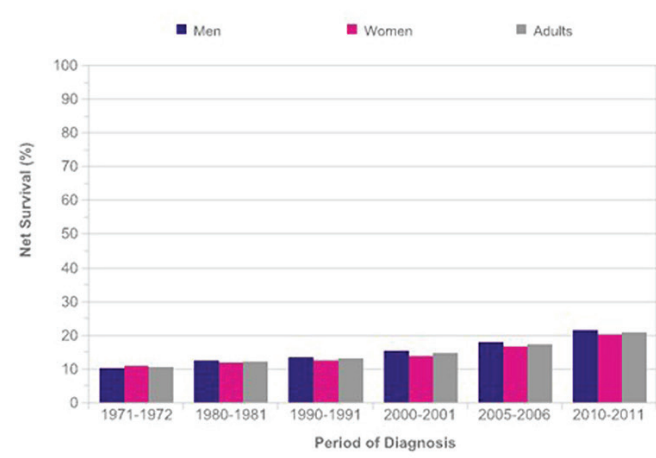

Age-Standardised Five-Year Net Survival, England and Wales

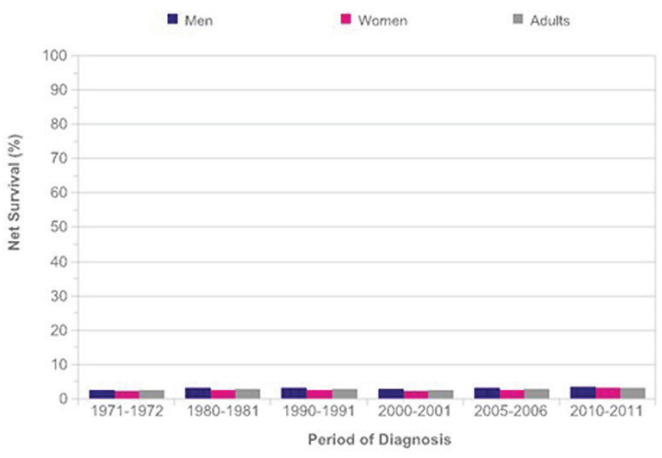

Figure 6. Pancreatic cancer, age-standardized 1-year and 5-year net survival, adults (age: 15 - 99 years), England and Wales 1971 - 2011 (reproduced from reference [34]).

Previous studies have shown that in both sexes, temporal trends in cigarette smoking prevalence were related to temporal trends in pancreatic cancer mortality [13, 20, 29]. In developed countries, decreased smoking, particularly in men, has been widely recognized as the main contributor to the decrease in mortality trends from pancreatic cancer [29], particularly in the USA, UK and Australia where the tobacco control started to be implemented earlier. Besides cigarette smoking, alcohol abuse, high consumption of saturated fat and reduced physical activity may also influence pancreatic cancer mortality. Interestingly, the fact that in underdeveloped countries like Africa there will be a dramatic increase of pancreatic cancer incidence and mortality suggesting that socioeconomic disparities have a significant impact on the trends, as improved diagnostic tools and access to therapies may be very limited.

Possible ways to reverse these trends and improve pancreatic cancer patient outcomes are through the prevention (lifestyle change) and more research and increased awareness of the disease and its symptoms. Early stage and small tumor size $(<2 \mathrm{~cm})$ are two important prognostic factors for pancreatic cancer [30]. Scientists and clinicians around the world are working tirelessly to solve some of pancreatic cancer's biggest questions. Indeed, it would be important to understand the mechanism that turns a healthy pancreatic cell into a cancerous one and to identify clues, or biomarkers that are present in the early and more treatable stage of the disease. These findings will consequently lead to new treatments that can selectively and effectively kill the cancer cells and lower the mortality rate with a higher expectation of survival.

\section{Survival}

Although every pancreatic cancer patient's case is unique, and it is not possible to predict each person outcome, populationwide studies reported that a person diagnosed with any cancer, including pancreatic cancer, will survive 5 years. From 2014 to 2018 , the 5-years survival rate for pancreatic cancer increased from $6 \%$ to $9 \%$, which shows that progress is being made and there is an urgent need to improve the survival even more. Indeed, to date, pancreatic cancer remains one of the most lethal malignancies, with a dismal prognosis and mortality/incidence ratio of $94 \%$ [1].

Despite significant differences in incidence and mortality rate between very high/high-human development index (HDI) regions and low-HDI regions, survival rates vary very little between them [1].

Over the period 2014 - 2018, the United States National Cancer Institute data for pancreatic cancer in both sexes and all races showed that $10 \%$ of people diagnosed at the local stage had a 5 -year survival rate of $32 \%$. If the cancer is at stage III, the 5 -year survival rate is $12 \%$. More than half $(52 \%)$ of people were diagnosed at stage IV and had a 5-year survival rate of 3\% [31]. EUROCARE-5 Working Group analyzed the cancer-registries data of patients diagnosed with pancreatic cancer from 2000 to 2007 in 29 European countries and showed that 5 -year survival rates were the highest in Croatia (10.9\%) and Belgium (10.5\%) in both sexes, while the lowest survival rates were reported in Malta $(0 \%)$ and Northern Ireland $(3.02 \%)$ $[32,33]$.

In the UK, the 1-year survival rate for pancreatic cancer in men has increased from $10 \%$ during the 1971 - 1972 period to $22 \%$ during the $2010-2011$ period. In women, 1-year survival has increased from $11 \%$ to $20 \%$ over the same period. However, the 5- and 10-year survival rates for pancreatic cancer have not shown much improvement since the early 1970s (Fig. 6) [34].

Survival rates of pancreatic cancer are affected by several factors, such as age, sex, type of cancer, staging at the time of diagnosis, tumor size, serum albumin level, treatment modalities, differences and availability of healthcare systems, and other factors including overall health and lifestyle [25, 32, 
Table 1. Survival Rates According to the Clinical Stage of Pancreatic Cancer

\begin{tabular}{lll}
\hline \multirow{2}{*}{ Clinical stage } & \multicolumn{2}{c}{ Five-year survival (\%) } \\
\cline { 2 - 3 } & Exocrine pancreatic cancer & PanNET treated with surgery \\
\hline IA & 14 & 61 \\
IB & 12 & 61 \\
II & 7 & 52 \\
III & 3 & 41 \\
IV & 1 & 16 \\
\hline
\end{tabular}

35-38]. Because pancreatic adenocarcinoma and the other less common exocrine cancers are usually diagnosed at stage III or IV, it has a very poor prognosis compared to PanNET, and even for those cases not treatable with surgery, the 5-year survival rate is $16 \%$ [39] (Table 1). Besides, pancreatic cancer survival rates may be influenced by factors such as the validity of the cancer registry, accuracy and quality of registration data and completeness of follow-up $[40,41]$.

\section{Etiology and Risk Factors}

The etiology of pancreatic cancer has been extensively studied and is the subject of numerous meta-analyses and pooled analyses. Thus far, several risk factors have been identified and can be divided into two categories: modifiable and non-modifiable risk factors [42].

\section{Modifiable risk factors}

Modifiable risk factors include smoking, alcohol, obesity, dietary factors and exposure to toxic substances.

\section{Smoking}

Over one thousand million people practice smoking of tobacco worldwide, and it represents the most important environmental factor for pancreatic cancer in the world. The International Agency for Research on Cancer has confirmed that smoking is causally associated with pancreatic cancer [13, 43]. The risk of pancreatic cancer increases with the duration of smoking and number of cigarettes smoked daily. The risk is nearly two times higher in smokers than in non-smokers [44-46]; additionally, a recent meta-analysis of 82 studies found that the relative risk $(R R)$ of pancreatic cancer was $R R=1.74$ for current and $\mathrm{RR}=1.2$ for former smokers and the risk persists for at least 10 years after smoking cessation [47-49].

In 2012, the European Prospective Investigation into Cancer (EPIC) study showed that the risk of pancreatic cancer increases for every five cigarettes smoked per day and also, the passive smoking can increase the risk of pancreatic cancer by $50 \%[49,50]$. While smoking prevalence has declined in many developed countries, it remains high in others and is increasing among women and in developing countries. For example, in 2011, a study estimated that around $26.2 \%$ of pancreatic cancers in men and $31.0 \%$ in women were linked to tobacco smoking in the UK [20], while in the world's two most populous nations, India and China, smoker users are home to more smokers than the entire population of Europe [51].

The risk of pancreatic cancer associated with smoking remains elevated after allowing for potential confounding factors such as alcohol consumption.

\section{Alcohol}

Based on many studies, the risk of pancreatic cancer is undoubtedly increased by high alcohol consumption (more than three drinks per day), whereas there was no association found with low-to-moderate alcohol intake [52-54]. A large casecontrol study in 2010 showed increased risk even at the consumption of $60 \mathrm{~g} /$ day or more of liquor (spirits) but found no association with beer or wine [55].

A recent study found that heavy alcohol consumption was associated with a significant increase of pancreatic cancer risk among current smokers (age-adjusted odds ratio $(\mathrm{OR})=4.04$, 95\% CI: 1.58 - 10.37), whereas it was not observed among non-smokers (age-adjusted OR $=2.01,95 \% \mathrm{CI}$ : $0.50-8.18$ ). Furthermore, low-to-moderate alcohol intake was associated with increased pancreas cancer risk among current smokers [56], suggesting that smoking can modify the alcohol-cancer relationship. However, the association between alcohol and smoking is very close. Therefore, it may be challenging to implicate alcohol as an independent risk factor for pancreatic cancer.

\section{Obesity}

Obesity is associated with increased risk for several types of cancer including pancreatic cancer [57]. Some studies found that obesity increases the incidence and mortality of pancreatic cancer $[58,59]$. A study by Li et al $[60]$ found that being overweight (body mass index (BMI): 25.0 - $29.9 \mathrm{~kg} / \mathrm{m}^{2}$ ) or obese $\left(\mathrm{BMI} \geq 30 \mathrm{~kg} / \mathrm{m}^{2}\right)$ during early adulthood is associated with a higher risk of pancreatic cancer. Furthermore, obesity at an older age (30 - 79 years) was associated with lower overall survival.

According to an American Cancer Society (ACR) study, in both sexes, risk of pancreatic cancer among obese was higher 
$(\mathrm{RR}=2.08)$ compared to people of healthy BMI (18.5 - 24.9 $\mathrm{kg} / \mathrm{m}^{2}$ ) [59]. A recent meta-analysis has confirmed the hypothesis that both general and abdominal fatness is associated with increased pancreatic cancer risk [61]. Besides, physical inactivity (which can contribute to fat accumulation and overweight) has been linked to increased risk of pancreatic cancer.

\section{Dietary factors}

It seems reasonable that diet would affect the risk of different digestive diseases and cancers, including those of the pancreas. Dietary factors impact up to $30-50 \%$ on pancreatic cancer, and there is evidence that certain foods are associated at higher risk, while others are even protective $[42,62,63]$.

Consumption of red meats (especially when cooked at high temperature), processed meats, cholesterol, fried foods and other foods containing nitrosamines may increase the risk of pancreatic cancer $[64,65]$. It is possible that carcinogens in meat and nitrite or N-nitroso compounds that are used for preserving processed meats are involved in pancreatic cancer [66]. The results of a meta-analysis that included 11 casecontrol studies showed that red meat intake increased the pancreatic cancer risk by about $48 \%$ (95\% CI: 1.25 - 1.76). On the other hand, high intake of vegetables and fruits, especially those enriched in citrus and antioxidants, has a protective action, decreasing the risk by $38 \%$ (95\% CI: $0.54-0.73)$ and 29\% (95\% CI: 0.59 - 0.84), respectively [67].

Also, another meta-analysis of 11 prospective studies found a positive association between pancreatic cancer incidence and high consumption of red (120 g/day) or processed meat $(50 \mathrm{~g} /$ day $)(\mathrm{RR}=1.13$ and $\mathrm{RR}=1.19$ respectively $)$ [68]. However, some studies have not supported these findings [69], or have provided support for the association among men only [70]. For example, the EPIC study found no association between pancreatic cancer risk and intake of red and processed meat, while poultry consumption was associated with an increased risk [71]. Interestingly, two studies reported that frequent nut consumption significantly lowers the risk of pancreatic cancer in women $[72,73]$. Additionally, in a large UK cohort study in 2016, mortality for pancreatic cancer was lower for low meat eaters (about 30-45\% lower mortality), as well as vegetarians and vegans (about 50\% lower mortality) compared with regular meat eaters [74].

\section{Occupational exposures}

The etiological fraction of pancreatic cancer due to occupational exposures (involving exposure to metalworking and pesticides) within a population was estimated at $12 \%$.

A meta-analysis of occupational exposures and pancreatic cancer reported an increased risk with nickel exposure [75]. However, in occupational settings, nickel may be associated with high concentrations of polychlorinated biphenyls, and the latter compounds could account for the observed increased risk $[76,77]$. Carcinogenic mechanisms of nickel may include increasing DNA methylation, inhibiting DNA repair and inducing apoptosis through the generation of reactive oxygen species [78-82].

Additionally, few studies have found a link between exposure to cadmium and arsenic and pancreatic cancer risk. Cadmium is a non-essential metal that is known to accumulate in the human pancreas increasing the risk and mortality of pancreatic cancer $[83,84]$. Cadmium is a well-established carcinogen that acts on different steps of carcinogenesis, inhibiting DNA repair and causing genomic instability [85-87]. Furthermore, it causes transdifferentiation of pancreatic cells, inhibits DNA repair and induces or regulates the activity of several oncogenes or tumor-suppressor proteins that are expressed in human pancreatic cancer $[83,88,89]$. Arsenic exposure has been associated with increased cancer risk [90], but regarding its association with pancreatic cancer, little has been published. A potential link between childhood exposure to milk powder contaminated with arsenic and an almost two-fold excess mortality due to pancreatic cancer was recently reported [91, 92]. Inorganic arsenic is a highly toxic and carcinogenic metalloid, which can induce oxidative stress leading to inhibition of DNA repair $[90,93,94]$ and DNA strand breaks as well as DNA adducts [95]. Moreover, alterations in the methylation status of oncogenes and tumor-suppressor genes, mediated by arsenic, may also play a role in carcinogenesis [96].

As opposite, selenium, which is an essential micronutrient [97, 98], has been inversely associated with several cancers including pancreatic [99-103], while only a small study published in 1989 showed an increased risk of pancreatic cancer due to high selenium levels [104]; however, no replication studies have been published. Aberrant expression patterns of some selenoproteins suggest that they are relevant in scavenging reactive oxygen species and diminishing oxidative damage $[105,106]$. Also, selenium may boost p53 activity, leading to either DNA repair or apoptosis [107]. Selenium also seems to play a role as the antagonist of arsenic, cadmium and lead, decreasing the oxidative stress caused by exposure to these elements [108, 109].

Finally, high-quality studies are called for on interactions between occupational, environmental and lifestyle factors as well as interactions between genes and the environment.

\section{Non-modifiable risk factors}

Risk factors that are not modifiable include gender, age, ethnicity, diabetes mellitus, family history of pancreatic cancer, genetic factors, chronic infections, non-O blood group and chronic pancreatitis.

\section{Gender}

Pancreatic cancer is more common in men than in women. Globally, the incidence of pancreatic cancer is 5.5 per 100,000 for men and 4.0 per 100,000 for women [1]. Pancreatic cancer occurs more in men possibly due to environmental or occupational risk factors as well as lifestyles such as heavy smoking habit and high alcohol intake in men; however, it is also possible that there may yet be undiscovered genetic factors influencing cancer incidence and mortality in males and females. 
Age

SEER Cancer Statistics review states that pancreatic cancer is predominantly a disease of an older population and most of the patients are older than 50 years [10]. Indeed, the risk of developing pancreatic cancer increases with age, with the highest peak occurring between 60 and 80 years of age $[1,8,12]$. It rarely occurs before the age of 40 years, and the average age for more than half of the cases of pancreatic adenocarcinoma is 71 years. The reason for this late age onset is not apparent yet. It may be possible that from the moment a pancreatic lesion or inflammatory condition occurs, it takes several years before it will eventually switch into a malignant neoplasm. However, further studies are needed in this subject.

\section{Ethnicity}

Many studies have shown significant differences in the incidence of pancreatic cancer between races [110-112]. Pancreatic cancer incidence rates for African-Americans are higher than Caucasians, while the incidence is the lowest in AsianAmericans and Pacific Islanders [113]. Generally, the risk of pancreatic cancer rate is considerably higher in black people than in any other racial group [114]. Differences in the incidence of pancreatic cancer between races can be attributed to modifiable risk factors such as diet, alcohol, smoking and vitamin D insufficiency.

Nevertheless, some population-based studies have reported that racial disparities in pancreatic cancer are not entirely explained by the known and suspected risk factors. Also, other factors such as genetic factors acquired mutations from known toxins, e.g. the ability to detoxify tobacco products, oncogene mutation and biomarker immune expression, may contribute to the increased risk of pancreatic cancer $[115,116]$. Studies comparing the oncogene mutations and biomarker immune expression among Chinese, Japanese and Western patients, showed that Asian patients with pancreatic cancer have different expressions of KRAS and p53 than Western patients [117, 118], suggesting that each race has genetic and molecular diversity that can affect the incidence of pancreatic cancer, and may also explain the difference in survival rates after treatment of pancreatic cancer in racial disparities. In general, it seems that Asian patients have a better survival rate than non-Asian patients [119].

\section{Diabetes mellitus}

The positive association between both types I and II diabetes and the risk of pancreatic cancer has been reported in numerous studies [63,120-124]. Pancreatic cancer burden study in Italian population estimated that diabetes is attributable to $9.7 \%$ of pancreatic cancers [125]. Diabetes mellitus may be associated with a 1.8-fold increase in the risk of developing pancreatic cancer, particularly in Asians and Hispanic men in comparison with Whites and Blacks [126, 127]. Pancreatic cancer risk decreases with the duration of diabetes, but a $30 \%$ excess risk persists for more than two decades after diagnosis of diabetes [128]. Oral anti-diabetic medications or insulin use were associated with a reduced risk of pancreatic cancer [126, 128]. Among some patients with pancreatic cancer and peripheral insulin resistance, removal of the tumor improved glucose metabolism [129], providing evidence that altered glucose metabolism may be a result of the tumor.

An in-depth study of the association between diabetes and risk of pancreatic cancer may become of fundamental importance for two main reasons: the possible use of recent onset diabetes as a marker of the disease and, in particular, as a specific marker of pancreatic cancer, and the selection of a population at risk for pancreatic cancer. For example, Gullo et al [130] suggested that insulin resistance and diabetes may be induced by precancerous conditions or undiagnosed cancer of the pancreas, although it was shown that the risk of pancreatic cancer is 1.5 - to 2-fold higher in type II diabetes even when impaired glucose tolerance is detected more than 5 years [131] or 10 years before the onset of cancer [132]. Therefore, further studies are needed to understand whether diabetes can predict the onset of pancreatic cancer or be a marker.

\section{Family history}

It is estimated that about $5-10 \%$ of individuals with pancreatic cancers report a family history of pancreatic cancer [20, 133136]. Familial pancreatic cancer is defined in most studies as families in which a pair of first-degree relatives (parent, sibling or child) have been diagnosed with pancreatic cancer. Prospective analysis of families with this malignant disease shows that first-degree relatives of individuals with familial pancreatic cancer have a nine-fold increased risk of pancreatic cancer over the general population [4]. This risk doubles when at least two first-degree relatives in the family have pancreatic cancer [137] and rise to 32 -fold higher in kindreds with three or more firstdegree relatives with pancreatic cancer [138]. Furthermore, evidence indicates that the risk is the highest in kindreds with familial pancreatic cancer with a case of young-onset pancreatic cancer (age $<50$ years) in the family compared with those without a young-onset case [139]. Patients with familial pancreatic cancer also have more precancerous lesions than those with sporadic pancreatic cancers [136] and have an augmented risk of developing extra-pancreatic cancers [140].

\section{Genetic factors}

Genetic variation or mutation (Germ-line mutation) plays an important role in increased risk of pancreatic cancer [141]. Approximately $10 \%$ of patients with pancreatic cancer have some genetic predisposition such as gene variations or alterations to developing the disease [142]. Several germ-line mutations have been identified to be involved in hereditary forms of pancreatic cancer, such as BRCA1, BRCA2, PALB2, ATM, CDKN2A, APC, MLH1, MSH2, MSH6, PMS2, PRSS1 and STK11 $[138,143]$. Pancreatic cancer is also found to be associated with some familial cancer syndromes such as hereditary non-polyposis colon cancer (Lynch syndrome), the familial 
atypical multiple mole melanoma syndrome, Peutz-Jeghers syndrome, hereditary breast and ovarian cancer syndrome, familial adenomatous polyposis and Li-Fraumeni syndrome.

Germ-line BRCA2 gene mutations account for the highest proportion of known causes of inherited pancreatic cancer and have been identified in $5-17 \%$ of families with familial pancreatic cancer [144-146]. PALB2 (partner and localizer of $B R C A 2$ ) has been identified as a pancreatic cancer susceptibility gene [147], and germ-line mutations are recorded in up to $3 \%$ of patients with familial pancreatic cancer [148, 149]. Furthermore, germ-line $C D K N 2 A$ gene mutations are noted generally in families with familial atypical multiple-mole melanoma, while germ-line STK11 mutations in patients with Peutz-Jeghers syndrome and germ-line PRSS1 mutations in people with hereditary pancreatitis [138]. Additionally, four main genes in inherited genetic mutations that have a special role in increased risk of pancreatic cancer include $K R A S, p 53$ and SMAD4 [150].

\section{Infection}

Gastric colonization with Helicobacter pylori $(H$. pylori) is also associated with greater risk of pancreatic cancer, with an estimated population attributable fraction of $4-25 \%$ [63]. A meta-analysis of seven studies reported an increased risk of pancreatic cancer in people infected with $H$. pylori [151] and that this effect is strain-specific (CagA-positive strain) [151, 152]. One hypothesized mechanism behind that is that $H$. pylori colonization enhances the pancreatic carcinogenic effect of $N$-nitrosamines conveyed by smoking or dietary sources [153]. This effect is modulated by host inflammatory responses to the organism, by various virulence and other properties of the $H$. pylori itself, and by the host-organism interactions. However, on the other hand, many studies did not observe any correlation between $H$. pylori infection and the risk of pancreatic cancer [154]. However, all together these data are not sufficient to drive conclusions, so further studies evaluating this association are needed.

Some studies have reported the association between pancreatic cancer with some chronic infections such as hepatitis $\mathrm{B}$ and $\mathrm{C}$ virus (HBV and $\mathrm{HCV}$ ) [155].

\section{ABO blood group}

The antigens of the ABO system are expressed on red blood cell membranes as well as on the surface of several other normal and pathological cells and tissues. Following the first clinical observations more than 60 years ago, the role of ABO blood group in cancer biology has been intensely studied by several investigators, and it is now widely recognized that $\mathrm{ABO}$ antigens are associated with the risk of developing several types of cancers, including pancreatic [156-160].

A study in the UK [161] and a six-country study [162] observed an increased risk of pancreatic cancer for blood group A individuals. A study in Italy [163] found an increased risk of pancreatic cancer among blood group B individuals, and also a cohort study in the USA [164] found increased risk for indi- viduals who self-reported blood types $\mathrm{A}, \mathrm{B}$ and $\mathrm{AB}$ compared with O. Finally, findings of genome-wide association study "Panscan I" showed an association between non-O blood group and pancreatic cancer [165], and their results were then replicated by Rizzato et al [166]. Studies about the association with ABO group and the overall survival are controversial. The study of Dandona et al [167] conducted on 417 patients also confirmed that non-O blood group is associated with an increased risk of developing pancreatic cancer. However, the overall survival was not affected by the blood type. By contrast, the study of Ben et al [155] on 1,431 Chinese patients found that the median overall survival of patients with blood type $\mathrm{O}$ was longer compared to non-O blood group. Multivariate analysis revealed that blood group $\mathrm{O}$ was an independent predictor of long-term survival in a study based on 627 patients undergoing resection for pancreatic ductal adenocarcinoma [168]. Finally, a study by Wang et al [169] failed to find evidence of an impact of ABO blood type on the prognosis of pancreatic cancer patients. Proposed mechanisms in support of this link include inflammation, immune-surveillance for malignant cells, intercellular adhesion and membrane signaling.

However, it now seems consolidated that altered ABO glycosyltransferase activity plays a crucial role in carcinogenesis, mainly by affecting cell proliferation, tumor invasion and metastatic spread [34, 170]. Interestingly, an association among non-O blood group, $H$. pylori colonization and risk of pancreatic cancer was described in a meta-analysis study [151]. The hypothesis is that the presence of the terminal A or B blood group antigens in gastrointestinal mucins influences the properties of $H$. pylori binding and thus, the risk of pancreatic cancer is more significant for non-O individuals with seropositivity for $H$. pylori.

\section{Pancreatitis and Pancreatic Cancer}

Pancreatitis is an inflammation of the pancreas that can be acute or chronic and induces pancreatic damage because the activation of digestive enzymes occurs before they are released in the small intestine and consequently, they attack the pancreas.

Recurrent bouts of acute pancreatitis can cause glandular damage and lead to chronic pancreatitis by inducing a progressive, destructive inflammatory process that ends in the total destruction of the pancreas and results in malabsorption of dietary nutrients, diabetes mellitus and severe, unrelenting pain [171].

In recent decades, accumulating evidence has defined that longstanding pre-existing chronic pancreatitis as a strong risk factor for pancreatic cancer [172-174]. However, only $1.8 \%$ of these patients will develop pancreatic cancer within 10 years from the diagnosis and 4\% after 20 years [175-177]. A considerable proportion of cases of pancreatitis is thought to be a consequence of pancreatic tumor-related ductal obstruction $[173,177-179]$, indicating that this condition can be either a risk factor or a sign of early disease.

Chronic pancreatitis has several causes such as hereditary and idiopathic, but alcohol abuse is the most frequent cause of it $[180,181]$. Although $\sim 70 \%$ of chronic pancreatitis cases were attributed to alcohol abuse, $\sim 95 \%$ of alcoholics never de- 
velop it [181]. Patients with hereditary pancreatitis (mutations associated cationic trypsinogen gene (PRSS1) and the serine protease inhibitor, Kazal type 1 gene (SPINK1)) have a risk to develop pancreatic cancer that is 50 - 60 times greater than expected [182]. The EUROPAC study, the largest study of hereditary pancreatitis to date reporting the incidence of pancreatic cancer in 112 families from 14 countries, confirms a high risk of pancreatic cancer in subjects with hereditary pancreatitis, regardless of underlying mutation [183]. Additionally, these mutations may increase the risk of pancreatitis diagnosis at younger ages, and in some of these patients, younger ages at diagnosis of pancreatic cancer [173, 181, 184]. Also, patients with hereditary pancreatitis may be at higher risk of pancreatic cancer than patients with other forms of pancreatitis $[173,181$, $183,185,186]$.

The association between long-standing chronic pancreatitis and cancer has now been established. Pancreatic cancer develops in the setting of chronic pancreatitis from all known etiologies but appears to require 30 - 40 years of inflammation before an appreciable percentage of patients develop pancreatic cancer.

\section{Screening and Prevention}

Early detection may be the key to reduce mortality and may be supported by patients' screening and prevention.

Screening of large groups in the general population is not currently considered effective to detect the disease at its early stage, although newer techniques, and the screening of tightly targeted groups (especially of those with family history), are being evaluated [187, 188], including blood markers for pancreatic cancer CA19-9, CA-50, SPAN-1, DUPAN-2, cell surface-associated mucins (MUC), carcinoembryonic antigen and heat shock proteins $[189,190]$. However, these tests have not been well studied yet. Furthermore, the focus of screening efforts up to now has been to detect preinvasive lesions, rather than early pancreatic cancer, since resection of preinvasive lesions can prevent development of an invasive pancreatic cancer, whereas once an invasive pancreatic cancer develops, its spread beyond the pancreas is probably rapid, restricting use of markers of invasive pancreatic cancer. Therefore, primary prevention is of utmost importance.

Understanding the etiology and illuminating the risk factors identifying high-risk individuals are essential to the primary prevention of this often rapidly fatal disease. The best preventive strategy against pancreatic cancer is risk reduction, acting on the modifiable risk factors (tobacco smoking, overweight and alcohol use, reducing red meat consumption and increasing fruit and vegetable intake, having regular exercise) and through regular control of health issues [12, 20, 48, 133].

Tobacco smoking is highly associated with pancreatic cancer risk, and it has been estimated that by prevention of smoking, about $30 \%$ of pancreatic cancers could be prevented [20]. Interestingly, after 10 years of smoking cessation, the risk is reduced to the levels of a non-smoker [49].

Dietary modification is important in preventing pancreatic cancer for several reasons. First, high consumption of red and processed meat is associated with greater risk of pancreatic cancer [64, 65], while high fruit and vegetable intake [67], as well as nut consumption, is found protective [72, 73]. Therefore, a well-balanced diet enriched in fruits, vegetables and vitamins is highly recommended. Also, lower intake of saturated fat, together with increased physical activity, is highly suggested to help to reduce the risk of overweight or obesity, which are also associated with risk of pancreatic cancer.

Patients who have cystic neoplasms of the pancreas develop pancreatic cancer in about approximately $60-70 \%$ of cases [191]. The complete extirpation of cystic neoplasms is now performed as a cancer preventive strategy [192]. Furthermore, limitation of alcohol use is necessary to reduce the risk of pancreatic cancer through the development of pancreatitis [181].

Non-modifiable risk factors cannot be controlled. However, patients with family history and genetic susceptibility may undergo screening tests for early detection of pancreatic cancer. Unfortunately, there are no screening tests yet available that may be widely applied, and researchers are working on developing effective screening tests. For people with high risk of pancreatic cancer (including patients with hereditary pancreatitis or with a family history of pancreatic cancer), some screening techniques, such as endoscopic ultrasound and spiral computerized tomography, are promising but have not been thoroughly evaluated [193]. There is no consensus about when to initiate the screening; however, in patients with hereditary pancreatitis (PRSS1 germ-line mutation) who have a higher risk of early onset of pancreatic cancer, screening can begin at the age of 40 years [194].

\section{Diagnosis}

Pancreatic cancer is mostly diagnosed in an advanced stage, and $80-90 \%$ of patients have unresectable tumors at the moment of diagnosis. There are several reasons because this occurs.

First, early-stage pancreatic cancer is usually clinically silent, and most people who present with symptoms attributable to pancreatic cancer have advanced disease. Symptoms are non-specific and include abdominal pain, jaundice, pruritus, dark urine and acholic stools, which may be presenting symptoms as a result of an obstruction within the biliary tree [195]. Furthermore, anorexia, weight loss (which can arise from anorexia), early satiety, dyspepsia and nausea occur too [196], while less common manifestations include panniculitis and depression. Given the wide range of non-specific symptoms, there are a broad number of diseases that need to be differentiated [7], which include but are not limited to: cholangitis, cholecystitis, cholelithiasis, choledocholithiasis, choledochal cysts, duodenal or gastric ulcers, gastritis, pancreatitis, abdominal aortic aneurysm, lymphomas, and primary or secondary cancers of the biliary tree, liver, pancreas, stomach or intestine. Therefore, diagnosis can be delayed or missed, which makes pancreatic cancer the most common tumor detected at the autopsy studies $[17,24]$. To date, there are several diagnostic tools available, such as abdominal ultrasonography, tri-phasic pancreatic-protocol CT (which is the standard for diagnosis and staging [197, 198]), magnetic resonance imaging (MRI) $[7,138]$ and endoscopic ultrasound-guided fine-needle aspira- 
tion for cytological diagnosis [7] (which sensitivity is reported to be about $80 \%$ [199]). Additionally, in symptomatic patients, measurement of blood levels of cancer antigen 19-9 can help to confirm the diagnosis and predict prognosis and recurrence after resection [200]; however, it cannot stand as an individual screening tool for asymptomatic patients because it is not tumor-specific [201].

Of note, diagnostic tools and the change in use of various diagnostic modalities vary between developed and undeveloped countries, which may explain the observed vast differences in incidence and mortality rates. For example, in 2012, Europe carried one-third of the overall incidence, which likely reflected the more accurate diagnosis of pancreatic cancer rather than etiology [19].

\section{Conclusions}

Pancreatic cancer is a global problem that requires a global solution. Although its etiology remains still mostly unknown, many risk factors have been identified, and among them, smoking has been widely recognized as the main contributor to the high mortality rates of pancreatic cancer [13, 29]. Healthcare professionals and policy makers could make more efforts to control the associated risk factors that may range from advocating for lifestyle changes, awareness campaigns and to imposing more strict smoking-related laws. Analysis of pancreatic cancer epidemiology may be the key to elucidating the etiology of pancreatic cancer and thus, the cornerstone of developing future cancer control strategies.

\section{Conflict of Interest}

None of the authors have conflict of interest.

\section{Ethics Approval}

No ethics approval needed

\section{Financial Support}

No funding to disclose.

\section{Author Contributions}

PR and TS are responsible for conception and design. PR, TS and $\mathrm{VG}$ are responsible for analysis, interpretation, drafting and critical revision of the article. PR, TS and VG are responsible for final approval of the article.

\section{References}

1. Bray F, Ferlay J, Soerjomataram I, Siegel RL, Torre LA,
Jemal A. Global cancer statistics 2018: GLOBOCAN estimates of incidence and mortality worldwide for 36 cancers in 185 countries. CA Cancer J Clin. 2018;68(6):394424.

2. Ferlay J EM, Lam F, Colombet M, Mery L, Pineros M, Znaor A, Soerjomataram I, et al. Global cancer observatory: cancer today. Lyon, France: International Agency for Research on Cancer. Available from: https:/gco.iarc. fr/today, Accessed 05 October 2018.

3. Bosetti C, Lucenteforte E, Silverman DT, Petersen G, Bracci PM, Ji BT, Negri E, et al. Cigarette smoking and pancreatic cancer: an analysis from the International Pancreatic Cancer Case-Control Consortium (Panc4). Ann Oncol. 2012;23(7):1880-1888.

4. Klein AP, Brune KA, Petersen GM, Goggins M, Tersmette AC, Offerhaus GJ, Griffin C, et al. Prospective risk of pancreatic cancer in familial pancreatic cancer kindreds. Cancer Res. 2004;64(7):2634-2638.

5. Hidalgo M, Cascinu S, Kleeff J, Labianca R, Lohr JM, Neoptolemos J, Real FX, et al. Addressing the challenges of pancreatic cancer: future directions for improving outcomes. Pancreatology. 2015;15(1):8-18.

6. Organization WH. World Cancer Report 2014. Accessed 06 October 2018.

7. De La Cruz MS, Young AP, Ruffin MT. Diagnosis and management of pancreatic cancer. Am Fam Physician. 2014;89(8):626-632.

8. Siegel RL, Miller KD, Jemal A. Cancer statistics, 2018. CA Cancer J Clin. 2018;68(1):7-30.

9. Mohammed S, Van Buren G, 2nd, Fisher WE. Pancreatic cancer: advances in treatment. World J Gastroenterol. 2014;20(28):9354-9360.

10. SEER Cancer Statistics Review, 1975-2013 [Internet]. National Cancer Institue, Bethesda, MD. 2016. Available from: https://seer.cancer.gov/csr/1975_2015/. Accessed 05 October 2018.

11. Malvezzi M, Carioli G, Bertuccio P, Rosso T, Boffetta P, Levi F, La Vecchia C, et al. European cancer mortality predictions for the year 2016 with focus on leukaemias. Ann Oncol. 2016;27(4):725-731.

12. Bosetti C, Bertuccio P, Negri E, La Vecchia C, Zeegers MP, Boffetta P. Pancreatic cancer: overview of descriptive epidemiology. Mol Carcinog. 2012;51(1):3-13.

13. Ezzati M, Henley SJ, Lopez AD, Thun MJ. Role of smoking in global and regional cancer epidemiology: current patterns and data needs. Int J Cancer. 2005;116(6):963971.

14. Willett WC. Diet and cancer. Oncologist. 2000;5(5):393404.

15. Genkinger JM, Spiegelman D, Anderson KE, Bernstein L, van den Brandt PA, Calle EE, English DR, et al. A pooled analysis of 14 cohort studies of anthropometric factors and pancreatic cancer risk. Int J Cancer. 2011;129(7):1708-1717.

16. Jarosz M, Sekula W, Rychlik E. Influence of diet and tobacco smoking on pancreatic cancer incidence in poland in 1960-2008. Gastroenterol Res Pract. 2012;2012:682156.

17. Avgerinos DV, Bjornsson J. Malignant neoplasms: discordance between clinical diagnoses and autopsy findings 
in 3,118 cases. APMIS. 2001;109(11):774-780.

18. Mathers CD, Fat DM, Inoue M, Rao C, Lopez AD. Counting the dead and what they died from: an assessment of the global status of cause of death data. Bull World Health Organ. 2005;83(3):171-177.

19. Ferlay J, Steliarova-Foucher E, Lortet-Tieulent J, Rosso S, Coebergh JW, Comber H, Forman D, et al. Cancer incidence and mortality patterns in Europe: estimates for 40 countries in 2012. Eur J Cancer. 2013;49(6):1374-1403.

20. Parkin DM, Boyd L, Walker LC. 16. The fraction of cancer attributable to lifestyle and environmental factors in the UK in 2010. Br J Cancer. 2011;105(Suppl 2):S77-81.

21. Parkin DM, Bray F, Ferlay J, Pisani P. Global cancer statistics, 2002. CA Cancer J Clin. 2005;55(2):74-108.

22. Oberstein PE, Olive KP. Pancreatic cancer: why is it so hard to treat? Therap Adv Gastroenterol. 2013;6(4):321337.

23. Levi F, Lucchini F, Negri E, La Vecchia C. Pancreatic cancer mortality in Europe: the leveling of an epidemic. Pancreas. 2003;27(2):139-142.

24. Sens MA, Zhou X, Weiland T, Cooley AM. Unexpected neoplasia in autopsies: potential implications for tissue and organ safety. Arch Pathol Lab Med. 2009;133(12):19231931.

25. Lambe M, Eloranta S, Wigertz A, Blomqvist P. Pancreatic cancer; reporting and long-term survival in Sweden. Acta Oncol. 2011;50(8):1220-1227.

26. Ilic M, Ilic I. Epidemiology of pancreatic cancer. World J Gastroenterol. 2016;22(44):9694-9705.

27. Wu W, He X, Yang L, Wang Q, Bian X, Ye J, Li Y, et al. Rising trends in pancreatic cancer incidence and mortality in 2000-2014. Clin Epidemiol. 2018;10:789-797.

28. Ferlay J EM, Lam F, Colombet M, Mery L, Pineros M, Znaor A, Soerjomataram I, et al. Global Cancer Observatory: Cancer Tomorrow. Lyon, France: International Agency for Research on Cancer. Accessed 07 October 2018. Available from: http://gco.iarc.fr/tomorrow/ graphic-isotype type $=1 \&$ population $=900 \&$ mode $=$ pop ulation \&sex $=0 \&$ cancer $=39 \&$ age_group $=$ value \&apc male $=0 \&$ apc $\_$female $=0$.

29. Weiss W, Benarde MA. The temporal relation between cigarette smoking and pancreatic cancer. Am J Public Health. 1983;73(12):1403-1404.

30. Agarwal B, Correa AM, Ho L. Survival in pancreatic carcinoma based on tumor size. Pancreas. 2008;36(1):e1520.

31. United States National Cancer Institute. Pancreatic cancer: statistics 2018, May. Available from: https://www. cancer.net/cancer-types/pancreatic-cancer/statistics. Accessed 07 October 2018.

32. Rossi S, Baili P, Capocaccia R, Caldora M, Carrani E, Minicozzi P, Pierannunzio D, et al. The EUROCARE-5 study on cancer survival in Europe 1999-2007: Database, quality checks and statistical analysis methods. Eur J Cancer. 2015;51(15):2104-2119.

33. Survival of cancer patients in Europe. European Cancer Registry (EUROCARE). http://www.eurocare.it. 2015, October. Accessed 05 October 2018.

34. Cancer Research UK, https://www.cancerresearchuk.org/ health-professional/cancer-statistics/statistics-by-cancertype/pancreatic-cancer/survival\#ref-2, Accessed October 202018.

35. Carrato A, Falcone A, Ducreux M, Valle JW, Parnaby A, Djazouli K, Alnwick-Allu K, et al. A Systematic Review of the Burden of Pancreatic Cancer in Europe: RealWorld Impact on Survival, Quality of Life and Costs. J Gastrointest Cancer. 2015;46(3):201-211.

36. Oh SY, Edwards A, Mandelson MT, Lin B, Dorer R, Helton WS, Kozarek RA, et al. Rare long-term survivors of pancreatic adenocarcinoma without curative resection. World J Gastroenterol. 2015;21(48):13574-13581.

37. Dimastromatteo J, Houghton JL, Lewis JS, Kelly KA. Challenges of pancreatic cancer. Cancer J. 2015;21(3):188-193.

38. Yamamoto T, Yagi S, Kinoshita H, Sakamoto Y, Okada K, Uryuhara K, Morimoto T, et al. Long-term survival after resection of pancreatic cancer: a single-center retrospective analysis. World J Gastroenterol. 2015;21(1):262268.

39. American Cancer Society. https://www.cancer.org/cancer/pancreatic-cancer/detection-diagnosis-staging/survival-rates.html. Accessed 10 October 2018.

40. Karim-Kos HE, de Vries E, Soerjomataram I, Lemmens V, Siesling S, Coebergh JW. Recent trends of cancer in Europe: a combined approach of incidence, survival and mortality for 17 cancer sites since the 1990s. Eur J Cancer. 2008;44(10):1345-1389.

41. Brenner H, Hakulinen T. Population-based monitoring of cancer patient survival in situations with imperfect completeness of cancer registration. Br J Cancer. 2005;92(3):576-579.

42. Midha S, Chawla S, Garg PK. Modifiable and non-modifiable risk factors for pancreatic cancer: A review. Cancer Lett. 2016;381(1):269-277.

43. Iarc Working Group on the Evaluation of Carcinogenic Risks to Humans. Tobacco smoke and involuntary smoking. IARC Monogr Eval Carcinog Risks Hum. 2004;83:11438.

44. Kuzmickiene I, Everatt R, Virviciute D, Tamosiunas A, Radisauskas R, Reklaitiene R, Milinaviciene E. Smoking and other risk factors for pancreatic cancer: a cohort study in men in Lithuania. Cancer Epidemiol. 2013;37(2):133139.

45. Mizuno S, Nakai Y, Isayama H, Kawahata S, Saito T, Takagi K, Watanabe T, et al. Smoking, family history of cancer, and diabetes mellitus are associated with the age of onset of pancreatic cancer in Japanese patients. Pancreas. 2014;43(7):1014-1017.

46. Pelucchi C, Galeone C, Polesel J, Manzari M, Zucchetto A, Talamini R, Franceschi S, et al. Smoking and body mass index and survival in pancreatic cancer patients. Pancreas. 2014;43(1):47-52.

47. Rastogi T, Devesa S, Mangtani P, Mathew A, Cooper N, Kao R, Sinha R. Cancer incidence rates among South Asians in four geographic regions: India, Singapore, UK and US. Int J Epidemiol. 2008;37(1):147-160.

48. Iodice S, Gandini S, Maisonneuve P, Lowenfels AB. Tobacco and the risk of pancreatic cancer: a review and me- 
ta-analysis. Langenbecks Arch Surg. 2008;393(4):535545.

49. Vrieling A, Bueno-de-Mesquita HB, Boshuizen HC, Michaud DS, Severinsen MT, Overvad K, Olsen A, et al. Cigarette smoking, environmental tobacco smoke exposure and pancreatic cancer risk in the European Prospective Investigation into Cancer and Nutrition. Int J Cancer. 2010;126(10):2394-2403.

50. Lynch SM, Vrieling A, Lubin JH, Kraft P, Mendelsohn JB, Hartge $\mathrm{P}$, Canzian F, et al. Cigarette smoking and pancreatic cancer: a pooled analysis from the pancreatic cancer cohort consortium. Am J Epidemiol. 2009;170(4):403413.

51. Tan D. Smoking in Asia: a looming health epidemic. Asian Scientist Magazine Read more from Asian Scientist Magazine at: https:/wwwasianscientistcom/2012/08/features/smoking-in-asia-looming-health-epidemic-2012/. 2012. Accessed 05 October 2018.

52. Wang YT, Gou YW, Jin WW, Xiao M, Fang HY. Association between alcohol intake and the risk of pancreatic cancer: a dose-response meta-analysis of cohort studies. BMC Cancer. 2016;16:212.

53. Lucenteforte E, La Vecchia C, Silverman D, Petersen GM, Bracci PM, Ji BT, Bosetti C, et al. Alcohol consumption and pancreatic cancer: a pooled analysis in the International Pancreatic Cancer Case-Control Consortium (PanC4). Ann Oncol. 2012;23(2):374-382.

54. Tramacere I, Scotti L, Jenab M, Bagnardi V, Bellocco R, Rota M, Corrao G, et al. Alcohol drinking and pancreatic cancer risk: a meta-analysis of the dose-risk relation. Int J Cancer. 2010;126(6):1474-1486.

55. Michaud DS, Vrieling A, Jiao L, Mendelsohn JB, Steplowski E, Lynch SM, Wactawski-Wende J, et al. Alcohol intake and pancreatic cancer: a pooled analysis from the pancreatic cancer cohort consortium (PanScan). Cancer Causes Control. 2010;21(8):1213-1225.

56. Rahman F, Cotterchio M, Cleary SP, Gallinger S. Association between alcohol consumption and pancreatic cancer risk: a case-control study. PLoS One. 2015;10(4):e0124489.

57. Davoodi SH, Malek-Shahabi T, Malekshahi-Moghadam A, Shahbazi R, Esmaeili S. Obesity as an important risk factor for certain types of cancer. Iran J Cancer Prev. 2013;6(4):186-194.

58. Berrington de Gonzalez A, Sweetland S, Spencer E. A meta-analysis of obesity and the risk of pancreatic cancer. Br J Cancer. 2003;89(3):519-523.

59. Calle EE, Rodriguez C, Walker-Thurmond K, Thun MJ. Overweight, obesity, and mortality from cancer in a prospectively studied cohort of U.S. adults. N Engl J Med. 2003;348(17):1625-1638.

60. Li D, Morris JS, Liu J, Hassan MM, Day RS, Bondy ML, Abbruzzese JL. Body mass index and risk, age of onset, and survival in patients with pancreatic cancer. JAMA. 2009;301(24):2553-2562.

61. Aune D, Greenwood DC, Chan DS, Vieira R, Vieira AR, Navarro Rosenblatt DA, Cade JE, et al. Body mass index, abdominal fatness and pancreatic cancer risk: a systematic review and non-linear dose-response meta-analysis of prospective studies. Ann Oncol. 2012;23(4):843-852.

62. Michaud DS, Skinner HG, Wu K, Hu F, Giovannucci E, Willett WC, Colditz GA, et al. Dietary patterns and pancreatic cancer risk in men and women. J Natl Cancer Inst. 2005;97(7):518-524.

63. Maisonneuve P, Lowenfels AB. Risk factors for pancreatic cancer: a summary review of meta-analytical studies. Int J Epidemiol. 2015;44(1):186-198.

64. Lightsey D. Comment on 'Red and processed meat consumption and risk of pancreatic cancer: meta-analysis of prospective studies'. Br J Cancer. 2012;107(4):754-755.

65. Stolzenberg-Solomon RZ, Cross AJ, Silverman DT, Schairer C, Thompson FE, Kipnis V, Subar AF, et al. Meat and meat-mutagen intake and pancreatic cancer risk in the NIH-AARP cohort. Cancer Epidemiol Biomarkers Prev. 2007;16(12):2664-2675.

66. Beaney AJ, Banim PJR, Luben R, Lentjes MAH, Khaw KT, Hart AR. Higher meat intake is positively associated with higher risk of developing pancreatic cancer in an age-dependent manner and are modified by plasma antioxidants: a prospective cohort study (EPIC-Norfolk) using data from food diaries. Pancreas. 2017;46(5):672678.

67. Paluszkiewicz P, Smolinska K, Debinska I, Turski WA. Main dietary compounds and pancreatic cancer risk. The quantitative analysis of case-control and cohort studies. Cancer Epidemiol. 2012;36(1):60-67.

68. Larsson SC, Wolk A. Red and processed meat consumption and risk of pancreatic cancer: meta-analysis of prospective studies. Br J Cancer. 2012;106(3):603-607.

69. Miller PE, Alexander D. A review and meta-analysis of prospective studies of red and processed meat and pancreatic cancer. FASEB J. 2016;30:902-909.

70. Aschebrook-Kilfoy B, Cross AJ, Stolzenberg-Solomon RZ, Schatzkin A, Hollenbeck AR, Sinha R, Ward MH. Pancreatic cancer and exposure to dietary nitrate and nitrite in the NIH-AARP Diet and Health Study. Am J Epidemiol. 2011;174(3):305-315.

71. Rohrmann S, Linseisen J, Nothlings U, Overvad K, Egeberg R, Tjonneland A, Boutron-Ruault MC, et al. Meat and fish consumption and risk of pancreatic cancer: results from the European Prospective Investigation into Cancer and Nutrition. Int J Cancer. 2013;132(3):617-624.

72. Bao Y, Hu FB, Giovannucci EL, Wolpin BM, Stampfer MJ, Willett WC, Fuchs CS. Nut consumption and risk of pancreatic cancer in women. Br J Cancer. 2013;109(11):2911-2916.

73. Wu L, Wang Z, Zhu J, Murad AL, Prokop LJ, Murad $\mathrm{MH}$. Nut consumption and risk of cancer and type 2 diabetes: a systematic review and meta-analysis. Nutr Rev. 2015;73(7):409-425.

74. Appleby PN, Crowe FL, Bradbury KE, Travis RC, Key TJ. Mortality in vegetarians and comparable nonvegetarians in the United Kingdom. Am J Clin Nutr. 2016;103(1):218-230.

75. Ojajarvi IA, Partanen TJ, Ahlbom A, Boffetta P, Hakulinen T, Jourenkova N, Kauppinen TP, et al. Occupational exposures and pancreatic cancer: a meta-analysis. Occup Environ Med. 2000;57(5):316-324. 
76. Bosch de Basea M, Porta M, Alguacil J, Puigdomenech E, Gasull M, Garrido JA, Lopez T, et al. Relationships between occupational history and serum concentrations of organochlorine compounds in exocrine pancreatic cancer. Occup Environ Med. 2011;68(5):332-338.

77. Porta M, Malats N, Jariod M, Grimalt JO, Rifa J, Carrato A, Guarner L, et al. Serum concentrations of organochlorine compounds and K-ras mutations in exocrine pancreatic cancer. PANKRAS II Study Group. Lancet. 1999;354(9196):2125-2129.

78. Hartwig A, Kruger I, Beyersmann D. Mechanisms in nickel genotoxicity: the significance of interactions with DNA repair. Toxicol Lett. 1994;72(1-3):353-358.

79. Hartwig A, Mullenders LH, Schlepegrell R, Kasten U, Beyersmann D. Nickel(II) interferes with the incision step in nucleotide excision repair in mammalian cells. Cancer Res. 1994;54(15):4045-4051.

80. Kasprzak KS. The role of oxidative damage in metal carcinogenicity. Chem Res Toxicol. 1991;4(6):604-615.

81. Lee YW, Klein CB, Kargacin B, Salnikow K, Kitahara J, Dowjat K, Zhitkovich A, et al. Carcinogenic nickel silences gene expression by chromatin condensation and DNA methylation: a new model for epigenetic carcinogens. Mol Cell Biol. 1995;15(5):2547-2557.

82. Ahamed M, Akhtar MJ, Siddiqui MA, Ahmad J, Musarrat J, Al-Khedhairy AA, AlSalhi MS, et al. Oxidative stress mediated apoptosis induced by nickel ferrite nanoparticles in cultured A549 cells. Toxicology. 2011;283(23):101-108.

83. Schwartz GG, Reis IM. Is cadmium a cause of human pancreatic cancer? Cancer Epidemiol Biomarkers Prev. 2000;9(2):139-145.

84. Kriegel AM, Soliman AS, Zhang Q, El-Ghawalby N, Ezzat F, Soultan A, Abdel-Wahab M, et al. Serum cadmium levels in pancreatic cancer patients from the East Nile Delta region of Egypt. Environ Health Perspect. 2006;114(1):113-119.

85. Hartwig A. Mechanisms in cadmium-induced carcinogenicity: recent insights. Biometals. 2010;23(5):951-960.

86. Schwerdtle T, Ebert F, Thuy C, Richter C, Mullenders LH, Hartwig A. Genotoxicity of soluble and particulate cadmium compounds: impact on oxidative DNA damage and nucleotide excision repair. Chem Res Toxicol. 2010;23(2):432-442.

87. Bertin G, Averbeck D. Cadmium: cellular effects, modifications of biomolecules, modulation of DNA repair and genotoxic consequences (a review). Biochimie. 2006;88(11):1549-1559.

88. Candeias S, Pons B, Viau M, Caillat S, Sauvaigo S. Direct inhibition of excision/synthesis DNA repair activities by cadmium: analysis on dedicated biochips. Mutat Res. 2010;694(1-2):53-59.

89. Waalkes MP, Cherian MG, Ward JM, Goyer RA. Immunohistochemical evidence of high concentrations of metallothionein in pancreatic hepatocytes induced by cadmium in rats. Toxicol Pathol. 1992;20(3 Pt 1):323-326.

90. Overall evaluations of carcinogenicity: an updating of IARC Monographs volumes 1 to 42. IARC Monogr Eval Carcinog Risks Hum Suppl. 1987;7:1-440.
91. Yorifuji T, Tsuda T, Doi H, Grandjean P. Cancer excess after arsenic exposure from contaminated milk powder. Environ Health Prev Med. 2011;16(3):164-170.

92. Yorifuji T, Tsuda T, Grandjean P. Unusual cancer excess after neonatal arsenic exposure from contaminated milk powder. J Natl Cancer Inst. 2010;102(5):360-361.

93. Straif K, Benbrahim-Tallaa L, Baan R, Grosse Y, Secretan B, El Ghissassi F, Bouvard V, et al. A review of human carcinogens - Part C: metals, arsenic, dusts, and fibres. Lancet Oncol. 2009;10(5):453-454.

94. Qin XJ, Hudson LG, Liu W, Ding W, Cooper KL, Liu KJ. Dual actions involved in arsenite-induced oxidative DNA damage. Chem Res Toxicol. 2008;21(9):1806-1813.

95. Pu YS, Jan KY, Wang TC, Wang AS, Gurr JR. 8-Oxoguanine DNA glycosylase and MutY homolog are involved in the incision of arsenite-induced DNA adducts. Toxicol Sci. 2007;95(2):376-382.

96. Reichard JF, Puga A. Effects of arsenic exposure on DNA methylation and epigenetic gene regulation. Epigenomics. 2010;2(1):87-104.

97. Brown KM, Arthur JR. Selenium, selenoproteins and human health: a review. Public Health Nutr. 2001;4(2B):593599.

98. Papp LV, Lu J, Holmgren A, Khanna KK. From selenium to selenoproteins: synthesis, identity, and their role in human health. Antioxid Redox Signal. 2007;9(7):775-806.

99. Amaral AF, Cantor KP, Silverman DT, Malats N. Selenium and bladder cancer risk: a meta-analysis. Cancer Epidemiol Biomarkers Prev. 2010;19(9):2407-2415.

100. Bardia A, Tleyjeh IM, Cerhan JR, Sood AK, Limburg PJ, Erwin PJ, Montori VM. Efficacy of antioxidant supplementation in reducing primary cancer incidence and mortality: systematic review and meta-analysis. Mayo Clin Proc. 2008;83(1):23-34.

101. Zhuo H, Smith AH, Steinmaus C. Selenium and lung cancer: a quantitative analysis of heterogeneity in the current epidemiological literature. Cancer Epidemiol Biomarkers Prev. 2004;13(5):771-778.

102. Bjelakovic G, Nikolova D, Simonetti RG, Gluud C. Antioxidant supplements for preventing gastrointestinal cancers. Cochrane Database Syst Rev. 2008;3:CD004183.

103. Etminan M, FitzGerald JM, Gleave M, Chambers K. Intake of selenium in the prevention of prostate cancer: a systematic review and meta-analysis. Cancer Causes Control. 2005;16(9):1125-1131.

104. Burney PG, Comstock GW, Morris JS. Serologic precursors of cancer: serum micronutrients and the subsequent risk of pancreatic cancer. Am J Clin Nutr. 1989;49(5):895900 .

105. Murawaki Y, Tsuchiya H, Kanbe T, Harada K, Yashima K, Nozaka K, Tanida O, et al. Aberrant expression of selenoproteins in the progression of colorectal cancer. Cancer Lett. 2008;259(2):218-230.

106. Jackson MI, Combs GF, Jr. Selenium and anticarcinogenesis: underlying mechanisms. Curr Opin Clin Nutr Metab Care. 2008;11(6):718-726.

107. Smith ML, Lancia JK, Mercer TI, Ip C. Selenium compounds regulate p53 by common and distinctive mechanisms. Anticancer Res. 2004;24(3a):1401-1408. 
108. Fowler BA, Whittaker MH, Lipsky M, Wang G, Chen XQ. Oxidative stress induced by lead, cadmium and arsenic mixtures: 30-day, 90-day, and 180-day drinking water studies in rats: an overview. Biometals. 2004;17(5):567568.

109. Schrauzer GN. Anticarcinogenic effects of selenium. Cell Mol Life Sci. 2000;57(13-14):1864-1873.

110. Brotherton L, Welton M, Robb SW. Racial disparities of pancreatic cancer in Georgia: a county-wide comparison of incidence and mortality across the state, 2000-2011. Cancer Med. 2016;5(1):100-110.

111. Shavers VL, Harlan LC, Jackson M, Robinson J. Racial/ ethnic patterns of care for pancreatic cancer. J Palliat Med. 2009;12(7):623-630.

112. Ma J, Siegel R, Jemal A. Pancreatic cancer death rates by race among US men and women, 1970-2009. J Natl Cancer Inst. 2013;105(22):1694-1700.

113. American Cancer Society. Cancer Facts and Figures 2014. https://www.cancer.org/research/cancer-facts-statistics/all-cancer-facts-figures/cancer-facts-figures-2014. html. 2014. Accessed 05 October 2018.

114. Yadav D, Lowenfels AB. The epidemiology of pancreatitis and pancreatic cancer. Gastroenterology. 2013;144(6):1252-1261.

115. Arnold LD, Patel AV, Yan Y, Jacobs EJ, Thun MJ, Calle EE, Colditz GA. Are racial disparities in pancreatic cancer explained by smoking and overweight/obesity? Cancer Epidemiol Biomarkers Prev. 2009;18(9):2397-2405.

116. Pernick NL, Sarkar FH, Philip PA, Arlauskas P, Shields AF, Vaitkevicius VK, Dugan MC, et al. Clinicopathologic analysis of pancreatic adenocarcinoma in African Americans and Caucasians. Pancreas. 2003;26(1):28-32.

117. Dong M, Nio Y, Tamura K, Song MM, Guo KJ, Guo RX, Dong YT. Ki-ras point mutation and p53 expression in human pancreatic cancer: a comparative study among Chinese, Japanese, and Western patients. Cancer Epidemiol Biomarkers Prev. 2000;9(3):279-284.

118. Song MM, Nio Y, Dong M, Tamura K, Furuse K, Tian $\mathrm{YL}, \mathrm{He} \mathrm{SG}$, et al. Comparison of K-ras point mutations at codon 12 and p21 expression in pancreatic cancer between Japanese and Chinese patients. J Surg Oncol. 2000;75(3):176-185.

119. Longnecker DS, Karagas MR, Tosteson TD, Mott LA. Racial differences in pancreatic cancer: comparison of survival and histologic types of pancreatic carcinoma in Asians, blacks, and whites in the United States. Pancreas. 2000;21(4):338-343.

120. Batabyal P, Vander Hoorn S, Christophi C, Nikfarjam M. Association of diabetes mellitus and pancreatic adenocarcinoma: a meta-analysis of 88 studies. Ann Surg Oncol. 2014;21(7):2453-2462.

121. Pezzilli R, Pagano N. Is diabetes mellitus a risk factor for pancreatic cancer? World J Gastroenterol. 2013;19(30):4861-4866.

122. McAuliffe JC, Christein JD. Type 2 diabetes mellitus and pancreatic cancer. Surg Clin North Am. 2013;93(3):619627.

123. Haugvik SP, Hedenstrom P, Korsaeth E, Valente R, Hayes A, Siuka D, Maisonneuve P, et al. Diabetes, smoking, alcohol use, and family history of cancer as risk factors for pancreatic neuroendocrine tumors: a systematic review and meta-analysis. Neuroendocrinology. 2015;101(2):133-142.

124. Stevens RJ, Roddam AW, Beral V. Pancreatic cancer in type 1 and young-onset diabetes: systematic review and meta-analysis. Br J Cancer. 2007;96(3):507-509.

125. Rosato V, Polesel J, Bosetti C, Serraino D, Negri E, La Vecchia C. Population attributable risk for pancreatic cancer in Northern Italy. Pancreas. 2015;44(2):216-220.

126. Li D, Tang H, Hassan MM, Holly EA, Bracci PM, Silverman DT. Diabetes and risk of pancreatic cancer: a pooled analysis of three large case-control studies. Cancer Causes Control. 2011;22(2):189-197.

127. Liao KF, Lai SW, Li CI, Chen WC. Diabetes mellitus correlates with increased risk of pancreatic cancer: a population-based cohort study in Taiwan. J Gastroenterol Hepatol. 2012;27(4):709-713.

128. Bosetti C, Rosato V, Li D, Silverman D, Petersen GM, Bracci PM, Neale RE, et al. Diabetes, antidiabetic medications, and pancreatic cancer risk: an analysis from the International Pancreatic Cancer Case-Control Consortium. Ann Oncol. 2014;25(10):2065-2072.

129. Permert J, Ihse I, Jorfeldt L, von Schenck H, Arnquist HJ, Larsson J. Improved glucose metabolism after subtotal pancreatectomy for pancreatic cancer. Br J Surg. 1993;80(8):1047-1050.

130. Gullo L, Pezzilli R, Morselli-Labate AM, Italian Pancreatic Cancer Study G. Diabetes and the risk of pancreatic cancer. N Engl J Med. 1994;331(2):81-84.

131. Everhart J, Wright D. Diabetes mellitus as a risk factor for pancreatic cancer. A meta-analysis. JAMA. 1995;273(20):1605-1609.

132. Huxley R, Ansary-Moghaddam A, Berrington de Gonzalez A, Barzi F, Woodward M. Type-II diabetes and pancreatic cancer: a meta-analysis of 36 studies. Br J Cancer. 2005;92(11):2076-2083.

133. Anand P, Kunnumakkara AB, Sundaram C, Harikumar $\mathrm{KB}$, Tharakan ST, Lai OS, Sung B, et al. Cancer is a preventable disease that requires major lifestyle changes. Pharm Res. 2008;25(9):2097-2116.

134. Jacobs EJ, Chanock SJ, Fuchs CS, Lacroix A, McWilliams RR, Steplowski E, Stolzenberg-Solomon RZ, et al. Family history of cancer and risk of pancreatic cancer: a pooled analysis from the Pancreatic Cancer Cohort Consortium (PanScan). Int J Cancer. 2010;127(6):1421-1428.

135. Permuth-Wey J, Egan KM. Family history is a significant risk factor for pancreatic cancer: results from a systematic review and meta-analysis. Fam Cancer. 2009;8(2):109117.

136. Shi C, Hruban RH, Klein AP. Familial pancreatic cancer. Arch Pathol Lab Med. 2009;133(3):365-374.

137. Greer JB, Whitcomb DC, Brand RE. Genetic predisposition to pancreatic cancer: a brief review. Am J Gastroenterol. 2007;102(11):2564-2569.

138. Vincent A, Herman J, Schulick R, Hruban RH, Goggins M. Pancreatic cancer. Lancet. 2011;378(9791):607-620.

139. Brune KA, Lau B, Palmisano E, Canto M, Goggins $\mathrm{MG}$, Hruban RH, Klein AP. Importance of age of on- 
set in pancreatic cancer kindreds. J Natl Cancer Inst. 2010;102(2):119-126.

140. Wang L, Brune KA, Visvanathan K, Laheru D, Herman J, Wolfgang C, Schulick R, et al. Elevated cancer mortality in the relatives of patients with pancreatic cancer. Cancer Epidemiol Biomarkers Prev. 2009;18(11):2829-2834.

141. Ghiorzo P. Genetic predisposition to pancreatic cancer. World J Gastroenterol. 2014;20(31):10778-10789.

142. Shi C, Daniels JA, Hruban RH. Molecular characterization of pancreatic neoplasms. Adv Anat Pathol. 2008;15(4):185-195.

143. Solomon S, Das S, Brand R, Whitcomb DC. Inherited pancreatic cancer syndromes. Cancer J. 2012;18(6):485491.

144. Murphy KM, Brune KA, Griffin C, Sollenberger JE, Petersen GM, Bansal R, Hruban RH, et al. Evaluation of candidate genes MAP2K4, MADH4, ACVR1B, and BRCA2 in familial pancreatic cancer: deleterious BRCA2 mutations in 17\%. Cancer Res. 2002;62(13):3789-3793.

145. Hahn SA, Greenhalf B, Ellis I, Sina-Frey M, Rieder H, Korte B, Gerdes B, et al. BRCA2 germline mutations in familial pancreatic carcinoma. J Natl Cancer Inst. 2003;95(3):214-221.

146. Couch FJ, Johnson MR, Rabe KG, Brune K, de Andrade M, Goggins M, Rothenmund H, et al. The prevalence of BRCA2 mutations in familial pancreatic cancer. Cancer Epidemiol Biomarkers Prev. 2007;16(2):342-346.

147. Jones S, Hruban RH, Kamiyama M, Borges M, Zhang X, Parsons DW, Lin JC, et al. Exomic sequencing identifies PALB2 as a pancreatic cancer susceptibility gene. Science. 2009;324(5924):217.

148. Slater EP, Langer P, Niemczyk E, Strauch K, Butler J, Habbe N, Neoptolemos JP, et al. PALB2 mutations in European familial pancreatic cancer families. Clin Genet. 2010;78(5):490-494.

149. Tischkowitz MD, Sabbaghian N, Hamel N, Borgida A, Rosner C, Taherian N, Srivastava A, et al. Analysis of the gene coding for the BRCA2-interacting protein PALB2 in familial and sporadic pancreatic cancer. Gastroenterology. 2009;137(3):1183-1186.

150. Klein AP. Genetic susceptibility to pancreatic cancer. Mol Carcinog. 2012;51(1):14-24.

151. Risch HA, Yu H, Lu L, Kidd MS. ABO blood group, Helicobacter pylori seropositivity, and risk of pancreatic cancer: a case-control study. J Natl Cancer Inst. 2010;102(7):502-505.

152. Risch HA, Lu L, Kidd MS, Wang J, Zhang W, Ni Q, Gao YT, et al. Helicobacter pylori seropositivities and risk of pancreatic carcinoma. Cancer Epidemiol Biomarkers Prev. 2014;23(1):172-178.

153. Risch HA. Etiology of pancreatic cancer, with a hypothesis concerning the role of N-nitroso compounds and excess gastric acidity. J Natl Cancer Inst. 2003;95(13):948960.

154. Chen XZ, Schottker B, Castro FA, Chen H, Zhang Y, Holleczek B, Brenner H. Association of helicobacter pylori infection and chronic atrophic gastritis with risk of colonic, pancreatic and gastric cancer: A ten-year follow-up of the ESTHER cohort study. Oncotarget. 2016;7(13):17182-
17193.

155. Ben Q, Wang K, Yuan Y, Li Z. Pancreatic cancer incidence and outcome in relation to $\mathrm{ABO}$ blood groups among Han Chinese patients: a case-control study. Int J Cancer. 2011;128(5):1179-1186.

156. Anstee DJ. The relationship between blood groups and disease. Blood. 2010;115(23):4635-4643.

157. Liumbruno GM, Franchini M. Beyond immunohaematology: the role of the ABO blood group in human diseases. Blood Transfus. 2013;11(4):491-499.

158. Franchini M, Favaloro EJ, Targher G, Lippi G. ABO blood group, hypercoagulability, and cardiovascular and cancer risk. Crit Rev Clin Lab Sci. 2012;49(4):137-149.

159. Franchini M, Liumbruno GM, Lippi G. The prognostic value of $\mathrm{ABO}$ blood group in cancer patients. Blood Transfus. 2016;14(5):434-440.

160. Zhang BL, He N, Huang YB, Song FJ, Chen KX. ABO blood groups and risk of cancer: a systematic review and meta-analysis. Asian Pac J Cancer Prev. 2014;15(11):4643-4650.

161. Macafee AL. ABO blood groups and carcinoma of pancreas. Ulster Med J. 1964;33(2):129-131.

162. Vioque J, Walker AM. [Pancreatic cancer and ABO blood types: a study of cases and controls]. Med Clin (Barc). 1991;96(20):761-764.

163. Annese V, Minervini M, Gabbrielli A, Gambassi G, Manna R. ABO blood groups and cancer of the pancreas. Int J Pancreatol. 1990;6(2):81-88.

164. Wolpin BM, Chan AT, Hartge P, Chanock SJ, Kraft P, Hunter DJ, Giovannucci EL, et al. ABO blood group and the risk of pancreatic cancer. J Natl Cancer Inst. 2009;101(6):424-431.

165. Amundadottir L, Kraft P, Stolzenberg-Solomon RZ, Fuchs CS, Petersen GM, Arslan AA, Bueno-de-Mesquita $\mathrm{HB}$, et al. Genome-wide association study identifies variants in the ABO locus associated with susceptibility to pancreatic cancer. Nat Genet. 2009;41(9):986-990.

166. Rizzato C, Campa D, Giese N, Werner J, Rachakonda PS, Kumar R, Schanne M, et al. Pancreatic cancer susceptibility loci and their role in survival. PLoS One. 2011;6(11):e27921.

167. Dandona M, Gao F, Linehan DC, Wang-Gillam A. Re: ABO blood group and the risk of pancreatic cancer. J Natl Cancer Inst. 2010;102(2):135-137; author reply 137.

168. Rahbari NN, Bork U, Hinz U, Leo A, Kirchberg J, Koch $\mathrm{M}$, Buchler MW, et al. AB0 blood group and prognosis in patients with pancreatic cancer. BMC Cancer. 2012;12:319.

169. Wang DS, Wang ZQ, Zhang L, Qiu MZ, Luo HY, Ren C, Zhang DS, et al. Are risk factors associated with outcomes in pancreatic cancer? PLoS One. 2012;7(7):e41984.

170. Hakomori S. Antigen structure and genetic basis of histoblood groups A, B and O: their changes associated with human cancer. Biochim Biophys Acta. 1999;1473(1):247266.

171. Etemad B, Whitcomb DC. Chronic pancreatitis: diagnosis, classification, and new genetic developments. Gastroenterology. 2001;120(3):682-707.

172. Ekbom A, McLaughlin JK, Karlsson BM, Nyren O, Grid- 
ley G, Adami HO, Fraumeni JF, Jr. Pancreatitis and pancreatic cancer: a population-based study. J Natl Cancer Inst. 1994;86(8):625-627.

173. Raimondi S, Lowenfels AB, Morselli-Labate AM, Maisonneuve P, Pezzilli R. Pancreatic cancer in chronic pancreatitis; aetiology, incidence, and early detection. Best Pract Res Clin Gastroenterol. 2010;24(3):349-358.

174. Duell EJ, Lucenteforte E, Olson SH, Bracci PM, Li D, Risch HA, Silverman DT, et al. Pancreatitis and pancreatic cancer risk: a pooled analysis in the International Pancreatic Cancer Case-Control Consortium (PanC4). Ann Oncol. 2012;23(11):2964-2970.

175. Yadav D, Whitcomb DC. The role of alcohol and smoking in pancreatitis. Nat Rev Gastroenterol Hepatol. 2010;7(3):131-145.

176. Hirota M, Shimosegawa T, Masamune A, Kikuta K, Kume K, Hamada S, Kihara Y, et al. The sixth nationwide epidemiological survey of chronic pancreatitis in Japan. Pancreatology. 2012;12(2):79-84.

177. Lowenfels AB, Maisonneuve P, Cavallini G, Ammann RW, Lankisch PG, Andersen JR, Dimagno EP, et al. Pancreatitis and the risk of pancreatic cancer. International Pancreatitis Study Group. N Engl J Med. 1993;328(20):1433-1437.

178. Bracci PM, Wang F, Hassan MM, Gupta S, Li D, Holly EA. Pancreatitis and pancreatic cancer in two large pooled case-control studies. Cancer Causes Control. 2009;20(9):1723-1731.

179. Olson SH. Selected medical conditions and risk of pancreatic cancer. Mol Carcinog. 2012;51(1):75-97.

180. Midha S, Sreenivas V, Kabra M, Chattopadhyay TK, Joshi YK, Garg PK. Genetically determined chronic pancreatitis but not alcoholic pancreatitis is a strong risk factor for pancreatic cancer. Pancreas. 2016;45(10):1478-1484.

181. Whitcomb DC. Inflammation and Cancer V. Chronic pancreatitis and pancreatic cancer. Am J Physiol Gastrointest Liver Physiol. 2004;287(2):G315-319.

182. Lowenfels AB, Maisonneuve P, Whitcomb DC. Risk factors for cancer in hereditary pancreatitis. International Hereditary Pancreatitis Study Group. Med Clin North Am. 2000;84(3):565-573.

183. Howes N, Lerch MM, Greenhalf W, Stocken DD, Ellis I, Simon P, Truninger K, et al. Clinical and genetic characteristics of hereditary pancreatitis in Europe. Clin Gastroenterol Hepatol. 2004;2(3):252-261.

184. Raimondi S, Maisonneuve P, Lohr JM, Lowenfels AB. Early onset pancreatic cancer: evidence of a major role for smoking and genetic factors. Cancer Epidemiol Biomarkers Prev. 2007;16(9):1894-1897.

185. Lowenfels AB, Maisonneuve P, DiMagno EP, Elitsur Y, Gates LK, Jr., Perrault J, Whitcomb DC. Hereditary pancreatitis and the risk of pancreatic cancer. International Hereditary Pancreatitis Study Group. J Natl Cancer Inst. 1997;89(6):442-446.

186. Lowenfels AB, Maisonneuve P, Whitcomb DC, Lerch MM, DiMagno EP. Cigarette smoking as a risk factor for pancreatic cancer in patients with hereditary pancreatitis. JAMA. 2001;286(2):169-170.

187. Greenhalf W, Grocock C, Harcus M, Neoptolemos J. Screening of high-risk families for pancreatic cancer. Pancreatology. 2009;9(3):215-222.

188. Shin EJ, Canto MI. Pancreatic cancer screening. Gastroenterol Clin North Am. 2012;41(1):143-157.

189. Hidalgo M. Pancreatic cancer. N Engl J Med. 2010; 362(17):1605-1617.

190. Cappelli G, Paladini S, D'Agata A. [Tumor markers in the diagnosis of pancreatic cancer]. Tumori. 1999;85(1 Suppl 1):S19-21.

191. Walsh RM, Vogt DP, Henderson JM, Hirose K, Mason T, Bencsath K, Hammel J, et al. Management of suspected pancreatic cystic neoplasms based on cyst size. Surgery. 2008;144(4):677-684; discussion 684-675.

192. Tanaka M, Fernandez-del Castillo C, Adsay V, Chari S, Falconi M, Jang JY, Kimura W, et al. International consensus guidelines 2012 for the management of IPMN and MCN of the pancreas. Pancreatology. 2012;12(3):183197.

193. Canto MI, Goggins M, Yeo CJ, Griffin C, Axilbund JE, Brune K, Ali SZ, et al. Screening for pancreatic neoplasia in high-risk individuals: an EUS-based approach. Clin Gastroenterol Hepatol. 2004;2(7):606-621.

194. Vitone LJ, Greenhalf W, Howes NR, Neoptolemos JP. Hereditary pancreatitis and secondary screening for early pancreatic cancer. Rocz Akad Med Bialymst. 2005;50:7384.

195. American gastroenterological association medical position statement: epidemiology, diagnosis, and treatment of pancreatic ductal adenocarcinoma. Gastroenterology. 1999;117(6):1463-1484.

196. Krech RL, Walsh D. Symptoms of pancreatic cancer. J Pain Symptom Manage. 1991;6(6):360-367.

197. Klauss M, Schobinger M, Wolf I, Werner J, Meinzer HP, Kauczor HU, Grenacher L. Value of three-dimensional reconstructions in pancreatic carcinoma using multidetector CT: initial results. World J Gastroenterol. 2009;15(46):5827-5832.

198. Wong JC, Lu DS. Staging of pancreatic adenocarcinoma by imaging studies. Clin Gastroenterol Hepatol. 2008;6(12):1301-1308.

199. Harewood GC, Wiersema MJ. Endosonography-guided fine needle aspiration biopsy in the evaluation of pancreatic masses. Am J Gastroenterol. 2002;97(6):1386-1391.

200. Tempero MA, Malafa MP, Al-Hawary M, Asbun H, Bain A, Behrman SW, Benson AB, 3rd, et al. Pancreatic adenocarcinoma, Version 2.2017, NCCN Clinical Practice Guidelines in Oncology. J Natl Compr Canc Netw. 2017;15(8):1028-1061.

201. Safi F, Roscher R, Bittner R, Schenkluhn B, Dopfer HP, Beger HG. High sensitivity and specificity of CA 19-9 for pancreatic carcinoma in comparison to chronic pancreatitis. Serological and immunohistochemical findings. Pancreas. 1987;2(4):398-403. 